NBER WORKING PAPER SERIES

\title{
THE EXPECTED, PERCEIVED, AND REALIZED INFLATION OF U.S. HOUSEHOLDS BEFORE AND DURING THE COVID19 PANDEMIC
}

\author{
Michael Weber \\ Yuriy Gorodnichenko \\ Olivier Coibion \\ Working Paper 29640 \\ http://www.nber.org/papers/w29640 \\ NATIONAL BUREAU OF ECONOMIC RESEARCH \\ 1050 Massachusetts Avenue \\ Cambridge, MA 02138 \\ January 2022
}

\begin{abstract}
We thank Tobias Hülden and Vitalia Yaremko for excellent research assistance. We thank Fernanda Nechio and conference participants at the 22nd IMF Jacques Polak Annual Research Conference for comments. Researcher(s)' own analyses calculated (or derived) based in part on data from Nielsen Consumer LLC and marketing databases provided through the NielsenIQ Datasets at the Kilts Center for Marketing Data Center at The University of Chicago Booth School of Business. The conclusions drawn from the NielsenIQ data are those of the researcher(s) and do not reflect the views of NielsenIQ. NielsenIQ is not responsible for, had no role in, and was not involved in analyzing and preparing the results reported herein. Ordering of author names is random. The views expressed herein are those of the authors and do not necessarily reflect the views of the National Bureau of Economic Research.
\end{abstract}

NBER working papers are circulated for discussion and comment purposes. They have not been peer-reviewed or been subject to the review by the NBER Board of Directors that accompanies official NBER publications.

(C) 2022 by Michael Weber, Yuriy Gorodnichenko, and Olivier Coibion. All rights reserved. Short sections of text, not to exceed two paragraphs, may be quoted without explicit permission provided that full credit, including $(\odot$ notice, is given to the source. 
The Expected, Perceived, and Realized Inflation of U.S. Households before and during the COVID19 Pandemic

Michael Weber, Yuriy Gorodnichenko, and Olivier Coibion

NBER Working Paper No. 29640

January 2022

JEL No. E2,E3

\section{ABSTRACT}

As the pandemic spread across the U.S., disagreement among U.S. households about inflation expectations surged along with the mean perceived and expected level of inflation. Simultaneously, the inflation experienced by households became more dispersed. Using matched micro data on spending of households and their macroeconomic expectations, we study the link between the inflation experienced by households in their daily shopping and their perceived and expected levels of inflation both before and during the pandemic. In normal times, realized inflation barely differs across observable dimensions but low income, low education, and Black households experienced a larger increase in realized inflation than other households did. Dispersion in realized and perceived inflation explains a large share of the rise in dispersion in inflation expectations.

Michael Weber

Booth School of Business

University of Chicago

5807 South Woodlawn Avenue

Chicago, IL 60637

and NBER

michael.weber@chicagobooth.edu

Yuriy Gorodnichenko

Department of Economics

530 Evans Hall \#3880

University of California, Berkeley

Berkeley, CA 94720-3880

and IZA

and also NBER

ygorodni@econ.berkeley.edu
Olivier Coibion

Department of Economics

University of Texas at Austin

2225 Speedway

Austin, TX 78712

and NBER

ocoibion@gmail.com 


\section{Introduction}

When the COVID19 pandemic spread across the U.S. and economic activity ground to a halt in many sectors, a basic question that policymakers faced was whether to think of this shock as supplydriven or as demand-driven. Many other economic players faced the question as well. As products like toilet paper disappeared from retailers' shelves and re-appeared online at hefty premiums, households had to ask themselves whether the shortage was coming from the panicked buying of other consumers, in which case they could wait for an increase in supply to quickly materialize, or from reduced production by manufacturers due to lockdowns or workers staying at home, in which case the shortage could be long-lived. Strikingly, the average inflation expectations of households rose, consistent with a supply-side interpretation, but disagreement among households about the inflation outlook also increased sharply. What was behind this pervasive disagreement? Was it that, like economists, households disagreed about whether the shock was a supply or a demand one? Or was it that they received different signals about the severity of the shock, due for example to the specific prices they faced in their regular shopping and heterogeneity in their shopping bundles? Understanding the answers to these questions can shed light not just on the pandemic period but more generally on the nature of household expectations, the degree of anchoring in inflation expectations, and the current inflation outlook as post-pandemic inflation rates spike.

In this paper, we study the sources of the rise in disagreement about the macroeconomic outlook, and inflation in particular, among U.S. households during the pandemic. To do so, we combine large-scale surveys of U.S. households with detailed information on their spending patterns. Spending data allow us to observe in detail the price patterns faced by individual consumers and thereby characterize what inflation rate households experienced in their regular shopping. The surveys allow us to measure households' perceptions about broader price movements and economic activity as well as their expectations for the future. Jointly, these data permit us to characterize the extent to which the specific price changes faced by consumers in their daily lives shaped their economic expectations during this unusual time. Using both the realized and perceived levels of inflation by households, we find a strong role for actual price changes in accounting for their perceptions of future price changes as well as their perceptions as to the severity of the pandemic-induced downturn.

Prices paid during shopping trips are a natural starting point to understand inflation expectations since they are the prices observed most easily and frequently by consumers. In the 
absence of direct news about inflation, households are likely to form beliefs about aggregate prices based on the prices they regularly observe (D'Acunto et al. 2021a,c,e). Consistent with this view, we show that the inflation rates of regularly purchased goods (e.g., food and beverages) experienced by U.S. households spiked at the same time during the pandemic as did inflation expectations. In the cross section of individuals, we find larger increases in realized inflation for black, low income, and low education individuals compared to others during the pandemic with small differences in realized inflation in normal times. Importantly, the dispersion in realized inflation rates also rose sharply during the pandemic, precisely when households also began to disagree more about the inflation outlook. Disparities in realized inflation primarily originated from the different patterns of spending across categories of goods combined with an unusually high dispersion in inflation across categories (i.e., from some households purchasing relatively more milk and others more soda). We then document a positive relationship between the realized inflation at the household level and households' inflation expectations. This relationship is particularly strong for less educated, lower income Americans: when they experience more inflation in their daily lives, they tend to expect higher inflation for the whole economy in the future. As a result, the widening dispersion in the inflation rates during the pandemic experienced by U.S. households provides one possible source for the rise in disagreement about future aggregate inflation during this period.

In addition to the experienced inflation of households, our survey also allows us to measure the perceived aggregate inflation of households, which has often been found to be a strong predictor of households' inflation expectations (Jonung 1981). Realized and perceived inflation can differ for a number of reassures. First, purchases reported in scanner data that we use to calculate realized inflation capture only about $20 \%-25 \%$ of the overall consumption expenditure of the typical household and heterogeneity across households in the unobserved component likely matters for perceived overall inflation rates. Second, behavioral biases may drive a wedge between the realized and perceived levels of inflation by households. For example, if some households confuse levels and changes (as found for gasoline in Coibion and Gorodnichenko 2015), survey based measures of perceived inflation would better represent households' beliefs than a measure of realized inflation. In addition, if households place disproportionate weight (relative to their expenditure shares) on certain goods when forming their perceptions (e.g., inflation expectations/perceptions are more sensitive to price variations for goods that are purchased more 
frequently, as documented in D'Acunto et al. 2021e), then expenditure-weighted measures of realized inflation would not adequately capture which goods drive households' perceptions of broader price movements. Consistent with this possibility, D’Acunto et al. (2021 a,c) show that many individuals think about concrete and specific products such as milk prices, which have large and disproportionate effects on perceived price changes at the aggregate level. Third, households may use information beyond their own experiences with prices to form beliefs about aggregate prices, such as the experience of friends and neighbors, news reports, or social media.

Like realized levels of inflation, the perceived rate of inflation by households spiked during the pandemic and was characterized by widespread disagreement. Consistent with Jonung (1981), the link between perceived and expected inflation also holds in the cross-section: households with the highest inflation expectations also tended to be those who thought that inflation had recently been high, a feature which holds within different income brackets, educational levels, ages, or geographic areas.

Importantly, we find that the link between perceived inflation and expected inflation is stronger than between realized inflation and expected inflation: while both are significantly related to inflation expectations, variation in perceived inflation can explain much more of the variation in expected inflation than can realized inflation, consistent with the advantages of a survey-based measure of perceptions of price changes. Quantitatively, the rise in disagreement about recent inflation rates perceived by households can account for much of the rise in disagreement about future inflation during the pandemic period ( $50 \%)$.

An alternative potential explanation for widespread disagreement about the inflation outlook during the pandemic is if households held different views about the nature of the shock: while a household with a supply-side view might expect prices to rise significantly with the COVID19induced recession, a household with a demand-side view should expect prices to fall. We find no evidence for this alternative explanation. The supply-side view of inflation taken by households during the pandemic is comparable to the one taken prior to the pandemic. Furthermore, this view is pervasive across all types of households: rich or poor, Americans who anticipate higher unemployment systematically expect higher inflation on average. As inflation disagreement spiked during the COVID19 crisis, so did disagreement about future unemployment, with those expecting a rapid recovery being the same people as those who expected lower inflation. Disagreement about the severity of the pandemic can qualitatively explain the dynamics of disagreement in expectations about aggregate inflation and unemployment among households. While economists and policy- 
makers may have disagreed amongst themselves about whether the pandemic was supply or demand driven, there was no comparable disagreement among U.S. households.

Our paper builds on several literatures. A first focuses on how households form macroeconomic beliefs, especially regarding inflation, and how those beliefs affect their decisions. In surveys of this literature, Coibion et al. (2020), Coibion, Gorodnichenko and Kamdar (2018), and D'Acunto et al. (2021d) argue that households appear to exhibit considerable departures from full-information rational expectations in the short run and households may be rather inattentive to monetary policy in countries with stable and low inflation (Binder 2017, Lamla and Vinogradov 2019). Bachmann, Berg and Sims (2015), D’Acunto, Hoang and Weber (2021b), Burke and Ozdagli (2021), Crump et al. (2015) and Andrade, Gautier and Mengus (2020) focus on how households' inflation expectations affect their spending decisions. We contribute to this literature by examining drivers of households' inflation expectation during the COVID19 crisis. Furthermore, while much of this literature has focused on mean expectations, we follow Mankiw, Reis, and Wolfers (2003) and Reis $(2020,2021)$ in also considering the disagreement across household expectations during the COVID19 crisis.

A second literature that we build on is the measurement of price changes at the individual level. The closest papers are Kaplan and Schulhofer-Wohl (2017) and D’Acunto et al. (2021e). Both use scanner data to document dramatic variation in inflation rates experienced at the household level. D’Acunto et al. (2021e) also show that realized inflation at the household level results in higher expected inflation rates, especially when weighting price changes by the frequency of purchase rather than expenditure shares. Another part of this literature (see Jaravel 2021 for a survey) examines heterogeneity in inflation trends for various types of households. Closely related is work by Cavallo, Cruces, and Perez-Truglia (2017) that considers how consumers' recall of recent shopping prices affect their inflation expectations. We build on these earlier studies and provide a comprehensive analysis of the joint dynamics of household-level expected, perceived, and realized inflation.

Third, our work is closely related to the recent literature studying the nature of the pandemic shock to the economy, such as Eichenbaum, Rebelo and Trabandt (2020). While the dynamics of professional forecasts are consistent with a demand-side view of the COVID19 crisis, households appear to have a supply-side view, akin to the stagflation in the 1970s (see e.g., Candia, Coibion, and Gorodnichenko 2020). Kamdar (2018) documents that this stagflationary view of inflation 
extends to the pre-COVID19 period. Using a series of randomized controlled trials, Andre et al. (2021) find that this pattern can apply more broadly: households do not view loose monetary policy as necessarily leading to better employment outcomes. We document that this pattern extends to the COVID19 crisis, i.e., households associate higher inflation with higher unemployment. This result is important not only for understanding macroeconomic dynamics during the crisis but also for policy communication. Specifically, if households hold this stagflationary view of inflation, attempts to raise inflation expectations can backfire as household could reduce consumer spending (due to e.g. precautionary motives) rather than increase it.

The results of the paper speak to recent policy debates on the degree to which household inflation expectations are anchored and the inflation outlook as prices in the U.S. begin to rise in the post-pandemic era. The importance of perceived inflation in explaining expected inflation points to one possible source of rising inflation expectations: even narrow types of price increases (like for used cars) can potentially lead to higher inflation expectations if they lead to sustained news coverage about recent inflation that makes households think that inflation is widespread rather than limited to narrow segments of the economy. Supply shortages in a few sectors therefore have the potential to move expectations well beyond their predicted impact from input-output effects if they are heavily covered by the news (Chahrour, Nimark and Pitschner 2020). Another possible danger stems from the disproportionate sensitivity of household perceptions and expectations to price changes for specific goods. Not all price changes are treated alike by households, and temporary shocks in certain sectors can have disproportionate effects on household expectations if the associated consumer products are the ones that household rely on to form broader expectations (Coibion and Gorodnichenko 2015). This point is already recognized by policymakers when it comes to gasoline, ${ }^{1}$ but it can apply to other goods that are purchased frequently as well, such as milk (D’Acunto et al. 2021c,e).

Our paper therefore provides one rationale for why expectations of inflation have risen so sharply during 2021 even though households tend to be inattentive to monetary policy and inflation dynamics. This rise in expectations should not be interpreted as a sign of de-anchoring: inflation expectations of households were never anchored in the first place (Candia et al. 2020, Weber et al.

\footnotetext{
${ }^{1}$ For example, in his June $16^{\text {th }} 2021$ press conference, Fed Chair Powell said, "So you'll see if gasoline prices were to spike, you'll see the shorter-term inflation expectation measures, particularly the surveys, move up. And, and that's, that's maybe not a good signal for future inflation if, if gas happens to spike and then go back down again.”
} 
2021). Instead, they reflect the fact that expectations are very sensitive to the prices experienced by households and when these rise sharply, they can have immediate and large effects on inflation expectations. To the extent that inflation expectations affect the decisions of households (e.g., Coibion, Gorodnichenko and Weber 2018) and firms (e.g., Coibion, Gorodnichenko and Ropele 2019), this suggests that inflationary spirals may develop rapidly when initial price changes are in goods that consumers frequently purchase.

The paper is organized as follows. Section 2 discusses how we measure individual rates of realized inflation and characterizes their dynamics around the pandemic. Section 3 describes the surveys of households that we implemented and presents results relating the aggregate inflation expectations of households to their perceived levels of inflation. Section 4 describes how realized, perceived and expected inflation relate to one another. Section 5 presents results on unemployment expectations of households. Section 6 concludes.

\section{Households' Experienced Inflation}

Households disagree systematically and pervasively about recent inflation dynamics, despite the fact that the latter is public information. One natural reason for this disagreement is if households rely on the prices that they observe in their own daily life to form beliefs about broader price changes, a view supported by D'Acunto et al. (2021e). In this section, we measure and describe the realized inflation of households both prior to and during the pandemic period.

\subsection{Measuring Realized Inflation}

To quantify the realized inflation at the individual household level, we rely on the Nielsen Homescan data, which contains individuals' purchases at the UPC (universal product code) level for specific categories of goods. These goods cover only a subset of households' total consumption, primarily food, beverages and small non-durable goods sold in grocery stores and other retailers. We focus on a sample of 43,135 households for whom we can construct 12 quarters of household inflation data from 2018Q1 to 2020Q4.

We first construct the effective price paid by each household $h$ over a quarter $t$ for each product module $j: p e_{j, t}^{h}{ }^{2}$ This effective price is defined as total expenditures for that module

\footnotetext{
${ }^{2}$ Example of a module are "BREAKFAST BARS”, “BAKING SODA”, “BAKERY - DESSERT CAKES - FROZEN”.
} 
divided by total volume (pounds, liters, etc.) purchased. We then quantify the effective inflation rate faced by a consumer for that module as $\pi_{j, t}^{h}=\log \left(\frac{p e_{j, t}^{h}}{p e_{j, t-1}^{h}}\right) \times 100$. Note that this effective inflation rate allows for household substitution across goods and stores within a product module, a margin that can be active over the business cycle (e.g., Coibion, Gorodnichenko and Hong 2015, Jaimovich, Rebelo and Wong 2019). We also note that using effective prices at the module level helps to address the limited overlap of purchases across time periods for narrowly defined products, i.e., we need a household to buy any type of milk in $t$ and $t-1$ rather than buy a particular UPC in both periods. To reduce the impact of extreme variations, we winsorize effective inflation/deflation at the module level for each household at $75 \%$. We then measure householdspecific realized inflation $\pi_{t}^{h}$ as the expenditure share-weighted average of module-specific

inflation rates: $\pi_{t}^{h}=\sum_{j \in B_{t}^{h}} \omega_{j, t}^{H} \pi_{j, t}^{h}$, where expenditure shares $\omega_{j, t}^{H}$ are the averages from the current period and previous period across all modules $j$ in household $h$ 's consumption basket $B_{t}^{h}$. Using information about current expenditure shares allows for household reallocation of spending within the period of inflation measurement, which may be particularly relevant during the COVID19 crisis (Cavallo 2020).

We use quarterly data for several reasons. First, this frequency conforms to the timing of surveys described in the next section. Second, using quarterly frequency yields more price observations per period thus reducing noise and outliers. Third, a quarterly frequency provides a better measure of consumption flows (Coibion, Gorodnichenko and Koustas 2021).

\subsection{Realized Inflation before and during COVID19}

We plot the resulting quarterly time series of the Huber robust mean of realized inflation in Figure 1 , along with the time series of the cross-sectional dispersion in realized inflation. The realized rate of inflation hovered around 2\% (annualized rate) prior to the pandemic, consistent with both broader measures of household inflation as well as more narrow ones focusing on food prices that are closer to the consumption bundle that we measure. However, we find significant dispersion in these rates of realized inflation, with a cross-sectional standard deviation of 5-6 percentage points. As shown in Panel B of Figure 1, the $90^{\text {th }}$ percentile of experienced quarter-on-quarter inflation rate is 6-7 percent, while the $10^{\text {th }}$ percentile is approximately $-4 \%$ at an annualized rate. Thus, 
differences in realized levels of inflation across households are very large, consistent with Kaplan and Schulhofer-Wohl (2017), even during relatively stable economic times.

Panel A of Figure 1 also shows that, as the pandemic spread, the realized level of inflation by U.S. households increased sharply, rising to almost 10 percent at an annualized rate in 2020Q2. This rise is consistent with the rate of inflation measured in that quarter by the Bureau of Labor Statistics for food prices and beverages, also shown in Panel A of Figure 1. Furthermore, the start of the pandemic was also associated with a sharp increase in the dispersion of realized inflation across households; the cross-sectional standard deviation rose almost $10 \%$ in one quarter. This increase primarily reflects a larger share of people experiencing higher rates of inflation, with the $75^{\text {th }}$ percentile of the realized inflation distribution rising from $4.5 \%$ in $2020 \mathrm{Q} 1$ to $5.9 \%$ in $2020 \mathrm{Q} 2$ at annualized rates.

Some differences in realized inflation across households are systematically related to household characteristics, as previously documented in Kaplan and Schulhofer-Wohl (2017). However, these observable characteristics explain little of the large dispersion observed in realized inflation rates in normal times. Figure 2 plots the time series of average realized inflation for different subgroups. Panel A plots the realized inflation by race. While e.g. Asian-Americans experience lower inflation rates on average than whites, we do see Blacks see the highest increase in realized inflation during the onset of the pandemic. Panel B plots realized inflation rates by income. Differences are consistent over time, although the difference in realized inflation between the richest and poorest households increases by 4\% (quarter on quarter) in 2020Q3. Differences in realized inflation by education are more stable, as shown in Panel C but still increase more for low- than for high-education individuals. More variation can be seen across regions, as shown in Panel D. While the North East saw a rise in realized quarterly inflation of nearly 2 percentage points from 2020Q1 through 2020Q3, those in the rest of the country experienced an average increase of 1.5 percentage points at a quarterly rate over that period. Appendix Figure 4 shows that the rise in realized inflation was particularly muted in the Mountain states and the West South Central states, with increases in quarterly inflation of just 1 percentage point at a quarterly rate. Variation in realized inflation can have different sources. One source is if households' expenditure weights across categories of goods differ and the inflation rates in these categories vary. 
Widespread variation in average realized inflation rates for different categories of goods existed. ${ }^{3}$ Panel A of Figure 3 plots the distribution of average realized inflation rates across categories: we can see a pronounced increase in the dispersion of price dynamics across categories of goods with the arrival of the pandemic. This dispersion occurred as some categories of goods experienced higher average inflation and others deflation. Panel B plots average (across households) realized inflation rates for select categories of goods that are commonly purchased, such as eggs, cereal and pasta. These specific categories experienced pronounced increases in their quarterly rate of inflation in 2020Q2, with increases of up 12 percentage points in annual terms. Some other commonly purchased goods like candy displayed declines in average realized inflation during the same period. To the extent that consumption patterns differ significantly across households, this variation in inflation across categories provides one source of differences in realized inflation.

A second potential source of variation in realized inflation comes from variation within categories, that is, households may purchase the same consumption baskets but pay different prices for identical or similar goods (e.g., a gallon of milk may cost more in Whole Foods than in Walmart). Figure 4 shows that within-category dispersion of realized inflation rates has been increasing over time but there is no clear spike in this dispersion during the COVID19 crisis. ${ }^{4}$ So variation in the prices of goods within categories cannot account for much of the rise in realized inflation during the pandemic.

In summary, using scanner data, we find that realized inflation spiked during the early months of the pandemic, which is consistent with official statistics. In addition, there was a pronounced increase in the cross-sectional variation in realized inflation at that time with some households facing discernably higher inflation than others. Although large heterogeneity in prices (and inflation) paid by households exists even for identical goods, differences in the composition of consumption baskets appear to be a main factor behind the increase in the across-household variation in experienced inflation.

\section{Perceived and Expected Inflation of U.S. Households Before and During COVID19}

\footnotetext{
${ }^{3}$ We compute the average (across households) inflation rate for product module $j$ as $\pi_{j, t}=H^{-1} \sum_{h} \pi_{j, t}^{h}$.

${ }^{4}$ We find the same qualitative results when we use within-category dispersion of effective prices.
} 
The celebrated island model of Lucas (1972) posits that idiosyncratic signals about the price level (e.g., specific prices paid by a given household or firm) can be an important factor for how economic players form their expectations about aggregate variables. Using data for households in normal times, D’Acunto et al. (2021e) provide direct empirical support for this prediction. ${ }^{5}$ Building on this work, we document the evolution of inflation expectation during the COVID19 crisis and relate variation in expected inflation to realized inflation. We also propose a survey analogue of realized inflation ("perceived inflation") over the previous twelve months.

\subsection{Measuring Expectations and Perceptions of Inflation by U.S. Households}

To measure the inflation expectations and perceptions of U.S. households, we rely upon a sequence of quarterly surveys sent to U.S. households participating in the Nielsen Homescan Panel from 2018Q1 through 2021Q2. Households that participate in the Homescan Panel record their purchases on a daily basis, as described in section 2.1. We implemented quarterly surveys of these households to measure their expectations. Approximately 80,000-90,000 households participate in the Nielsen Homescan Panel, and response rates to our surveys averaged around 20\% over time, yielding an average number of respondents of approximately 25,000 per wave. ${ }^{6}$ Since households participate in the Homescan Panel repeatedly, our survey has an important panel component to it as well. Nielsen also provides sampling weights to ensure the panel is representative of the U.S. population. Hence, our survey is superior to existing surveys of households along multiple dimensions. First, its size is much larger than other surveys of inflation expectations. Second, it has an important panel dimension. Third, it can be mapped to underlying data on the spending of households and the prices they pay at a high frequency.

To measure perceptions and expectations of inflation, we rely on several questions posed to respondents. One such question asks respondents to provide a point forecast of inflation over the next twelve months. Specifically, we ask:

\footnotetext{
${ }^{5}$ In a similar spirit, Andrade et al. (2021) document that French firms revise their macroeconomic expectations in response to industry-specific, idiosyncratic shocks.

${ }^{6}$ More than one household member can participate in our surveys.
} 
What do you think the inflation rate (as measured by the Consumer Price Index) is going to be over the next 12 months? Please provide an answer as a percentage change from current prices. $\%$

If you think there was inflation, please enter a positive number. If you think there was deflation, please enter a negative number. If you think there was neither inflation nor deflation, please enter zero.

This question was asked to almost all respondents across waves and is similar to the formulation used by the University of Michigan's Survey of Consumers (MSC), albeit with reference to CPI inflation rather than "prices in general." However, in many waves, this question was asked after participants were provided with some information about inflation or monetary policy, so we only utilize responses from households that were not provided with any additional information. Table 1 presents the number of responses to this question available for each wave. In three waves (2018Q3, 2019Q2, 2019Q3), this question was not asked at all due to space constraints.

All households were asked a distributional question regarding future inflation, in which they must assign probabilities to different possible outcomes for inflation, similar to the formulation used by the Federal Reserve Bank of New York's Survey of Consumer Expectations (SCE). Specifically, we asked:

In this question, you will be asked about the PERCENT CHANCE of something happening. The percent chance must be a number between 0 and 100 and the sum of your answers must add up to 100. What do you think is the percent chance that, over the next 12 months...

- $\quad$ the rate of inflation will be $12 \%$ or more

- $\quad$ the rate of inflation will be between $8 \%$ and $12 \%$

- $\quad$ the rate of inflation will be between $4 \%$ and 8

- $\quad$ the rate of inflation will be between $2 \%$ and 4

- $\quad$ the rate of inflation will be between $0 \%$ and $2 \%$

- $\quad$ the rate of deflation (opposite of inflation) will be between $0 \%$ and $2 \%$

- $\quad$ the rate of deflation (opposite of inflation) will be between $2 \%$ and $4 \%$

- $\quad$ the rate of deflation (opposite of inflation) will be between $4 \%$ and $8 \%$

- $\quad$ the rate of deflation (opposite of inflation) will be between $8 \%$ and $12 \%$

- $\quad$ the rate of deflation (opposite of inflation) will be $12 \%$ or more $\%$ Total 
where the survey software constructs and shows respondents the sum of probabilities they assign and requires it to equal $100 \%$ before they can continue. From responses to this question, one can construct mean estimates (assuming uniform distributions within each bin and fixed endpoint values for extreme bins) as well as measures of uncertainty (such as the standard deviation in the forecast).

This exact formulation of the question was used in surveys during 2018. In the 2019 waves, the same question was used but the ordering of the bins was reversed: deflation bins were presented before inflation bins. Starting in 2020Q1, the ordering of the bins was randomized, with half of respondents receiving the inflation bins first while the other half were presented with deflation bins first. In practice, the ordering of the bins makes a difference for responses provided by households, with average responses being significantly lower when deflation bins are presented first. We can see this point by regressing mean forecasts of respondents in 2020 waves from these distribution questions on an indicator variable equal to one if their formulation of the questions had deflation ordered first. On average, inflation forecasts are 0.8 percentage points lower with this ordering than when inflation bins are ordered first. The ratio of standard deviations for implied means is 1.1, i.e., dispersion is a bit higher when inflation bins are ordered first. We use these moments to adjust implied means based on responses to the question with deflation bins ordered first so that they have the same moments as the responses to the question with inflation bins ordered first. While the survey does not systematically include expectations of inflation at longer horizons, it has been extensively documented that the short-run and longer-run inflation expectations of households tend to move in lockstep (Candia et al. 2020, Weber et al. 2021). As a result, one would expect the dynamics of 12 month ahead inflation expectations of households to speak directly to the dynamics of longer-run inflation expectations over this time period. Furthermore, empirical evidence indicates that exogenous changes in the 12-month ahead inflation expectations of households have pronounced and immediate effects on the spending decisions of households (Coibion, Georgarakos, Gorodnichenko and van Rooij 2019, Coibion, Gorodnichenko and Weber 2018).

\subsection{The Dynamics of Expected Inflation}

Due to the widespread presence of large outliers in surveys of household inflation beliefs, we use Huber regressions to systematically identify and control for outliers in our data. We plot the resulting mean and cross-sectional standard deviation of inflation expectations measured using point forecasts in Panel A of Figure 5. Prior to the COVID19 pandemic, the 12-month-ahead 
inflation expectations of households were trending down from 4\% in 2018 to around 2-3\% in 2019, well above the Federal Reserve's inflation target of $2 \%$. Significant dispersion in the inflation forecasts of households existed, with a cross-sectional standard deviation of about 3 percentage points, significantly more than what is commonly observed in surveys of professional forecasters (Coibion, Gorodnichenko and Weber 2018, Coibion et al. 2020).

With the arrival of the COVID19 pandemic in March of 2020, we see a large and immediate increase in the average inflation expectations of U.S. households in 2020Q2, to nearly 5\%, and remaining close to $4 \%$ through 2020, before rising to over 6\% in 2021Q2. ${ }^{7}$ In contrast, the inflation expectations of professional forecasters fell during this time period (Candia et al. 2020). A similar pattern is visible in the amount of disagreement about future inflation across households: the standard deviation in inflation forecasts rises to nearly 5 percentage points in 202Q1. As shown in Appendix Figure 1, this rise in both the mean and dispersion of inflation expectations is primarily driven by a sharp increase in the number of responses pointing to very high levels of expected inflation: the $10 \%$ and $25 \%$ percentiles of the distribution are little changed during this time period, and the median response increases less than the mean. ${ }^{8}$

These results do not hinge on using point forecasts to measure expectations. Panel B replicates the time series of mean and dispersion in household inflation forecasts using answers to distributional questions instead. The increase in expected inflation in 2020Q2 is smaller than with point forecasts (recall that the top inflation bin is $12 \%$ or more which we code as $14 \%$ ) but a large increase is visible in 2020Q3 instead, so both inflation measures point to a rise in expected inflation of at least 1 percentage point over this time period. The increase in the dispersion of expected inflation is also pronounced using the distributional question. As shown in Appendix Figure 1, the rise again primarily reflects an increase in the share of high inflation forecasts (the $90^{\text {th }}$ percentile rises from $5 \%$ to $8 \%$ ), but we also observe more deflationary answers (the $10^{\text {th }}$ percentile goes from $-0.5 \%$ in $2020 \mathrm{Q} 1$ to $-2 \%$ in 2020Q2). In short, both formulations of the inflation expectation question indicate a large increase in disagreement about the inflation outlook among households as the pandemic spread across the United States.

\footnotetext{
${ }^{7}$ Similar patterns are observed for other advanced economies, see e.g. Gautier et al. (2020).

${ }^{8}$ This pattern is central for understanding why other household inflation surveys (like the MSC or SCE) do not find such a large increase in inflation expectations at the start of COVID19. The statistics released from these surveys censor responses above a time-invariant threshold and focus on the median response.
} 


\subsection{Expected Inflation vs. Realized Inflation}

How do households' experiences with actual prices affect both their perceived and expected levels of aggregate inflation? In this section, we provide new evidence on the extent to which the prices paid by individual households shape their beliefs about the broader economy. As a first step, Figure 6 plots binscatters linking households' realized inflation with their expected inflation. We can observe a strong positive relationship between inflation expectations and realized inflation. We provide additional evidence on the strength of these relationships in Appendix Table 1, which presents results from regressing expected inflation on realized inflation of households along with household controls, household fixed effects, time fixed effects and combinations thereof. In all cases, the realized inflation of households remains a strong predictor of households' inflation expectations consistent with evidence in D'Acunto et al. (2021e).

The role of realized inflation in shaping views about future aggregate inflation is related to a number of household characteristics. To see this, Figure 7 plots binscatters of realized inflation against expected inflation by race. Realized inflation is closely related to expected inflation for white and black households, but less so for Hispanics and not for Asian-American or Hispanic households. Appendix Figure 5 presents results for other sample splits. The strength of the relationship between realized inflation and expected inflation is decreasing in education: those with a high school education or less display a strong positive relationship between the inflation they experience in their daily lives and the inflation they expect for the aggregate economy, while highly educated households display no such relationship. A similar pattern can be observed along income levels. Higher realized inflation predicts higher expected inflation for low- and highincome households but less so middle-income households. However, there is little effect of age: the positive relationship between realized and expected inflation holds within all age groups. It can also be found in different parts of the country, although the pattern is strongest in the Midwest.

Hence, the realized inflation of households has an effect on what they expect about the future. However, the relationship appears to be noisy and many factors can contribute to the noise. First, our measure of realized inflation relies on prices for food items and small non-durables. To the extent prices of other goods and services move differentially, we may mismeasure realized inflation for the full consumption basket. For example, the price of gasoline, a salient price and a strong predictor of households' inflation expectations, is not available in Nielsen Homescan. Second, we use 
expenditure shares to aggregate product-module inflation rates. D’Acunto et al. (2021e) show that using frequency of purchase as weights can produce a stronger predictor of expected inflation. Intuitively, households are more likely to have a sense of changes in prices when they shop for milk (a relatively homogenous, frequently purchased good) than when they shop for refrigerators (a relatively heterogenous good that is not purchased frequently). Third, when households construct their prediction for "the general level of prices" or a specific price index, they may use weights that are different from the expenditure shares in the CPI or even their own consumption baskets (e.g., Kumar et al. 2015). For example, households can assign a greater weight to energy prices than is justified by expenditure shares and, more generally, salient prices may be overweighted (D'Acunto et al. 2021c). Finally, households commonly confuse changes and levels of prices: a much stronger relationship exists between inflation expectations and recent experienced price levels, as found in Coibion and Gorodnichenko (2015) for the case of gasoline prices.

Fortunately, we can ask households directly to report their beliefs about past inflation and thus bypass some of the thorny challenges in constructing realized inflation at the household level. Indeed, because households are more likely to apply the same notion of inflation when they form their beliefs about past and future inflation, the relationship between inflation perceptions and inflation expectations could be less noisy. Consistent with this insight, Jonung (1981) showed that Swedish households' inflation expectations have historically been strongly predicted by their perceived levels of inflation.

\subsection{Perceived Inflation by U.S. Households around the Pandemic}

We measured inflation perceptions using point estimates provided by households in response to the following question:

We would like to ask you some questions about the overall economy and in particular about the rate of inflation/deflation (Note: inflation is the percentage rise in overall prices in the economy, most commonly measured by the Consumer Price Index and deflation corresponds to when prices are falling). Over the last 12 months, what do you think the overall rate of inflation/deflation has been in the economy?

Answer: The rate of inflation/deflation was percent over the last 12 months. 
If you think there was inflation, please enter a positive number. If you think there was deflation, please enter a negative number. If you think there was neither inflation nor deflation, please enter zero.

This question was consistently asked of almost all participants in the survey and it was asked before eliciting inflation expectations. The main exception is in 2020Q4, when this question was not asked at all due to space constraints. For other waves starting in 2020Q3, due to space constraints, this question was asked for only half of the respondents (randomly chosen), with the other half receiving the question about the point forecast for 12-month ahead inflation. As a result, the number of households for which we observe point estimates of both perceived and expected inflation is somewhat limited, but we consistently have overlap with inflation forecasts constructed from implied means of distributional questions.

As we discuss above, the rise in household inflation expectations at the start of the pandemic could in principle reflect a number of sources or mechanisms. For example, the large stimulus package passed in March of 2020 and the early expansionary policies pursued by the Federal Reserve could have led households to anticipate a surge in prices in future months. ${ }^{9}$ Another possibility is that households were perceiving a high level of inflation at the time and were expecting this trend to continue.

To investigate the extent to which this latter hypothesis held up during the pandemic, Panel A of Figure 8 plots the equivalent time series as in Figure 5 but for the perceived levels of inflation of U.S. households during this time period. As with inflation expectations, households perceived recent levels of inflation to be slightly higher than the $2 \%$ level targeted by the Federal Reserve in 2018 and 2019, but this perceived level of inflation rose sharply between the first quarter and the third quarter of 2020 as the pandemic spread across the U.S. By 2020Q3, households' perceptions of inflation had risen by one percentage point on average. As with expectations, this rise in mean levels was accompanied by an increase in disagreement. As shown in Appendix Figure 2, this rise in disagreement is again primarily driven by a sharp rise in people reporting that inflation had been very high: the $75^{\text {th }}$ percentile of the distribution rose from $3 \%$ prior to the pandemic to $5 \%$ in the second half of 2020, with an even larger increase in the $90^{\text {th }}$ percentile of the distribution. Hence,

\footnotetext{
${ }^{9}$ For example, Coibion, Gorodnichenko and Weber (2021) find that informing households about high projected public debt or fiscal deficits raises inflation expectations.
} 
the dynamics of inflation expectations during this period are very similar to what we observe for the perceived level of inflation by households.

A similarly strong relationship between perceived and expected levels of inflation holds in the cross-section as well as the time series dimension. To see this pattern, Panel B of Figure 8 plots a binscatter of households' perceived levels of inflation against their expected levels of inflation (from point forecasts) both before COVID19 as well as during the pandemic. During both periods, we observe a strong positive relationship between households' perceived levels of inflation and their expectations about future inflation. Furthermore, the dispersion of both perceived and expected inflation is greater during the COVID19 period than before, consistent with the time series evidence in Figure 5. Table 2 presents additional evidence on the crosssectional evidence linking perceived and expected inflation. This relationship holds across different types of households, whether we separate them by age, income, education or gender. In all cases, we can observe a strong relationship between the recent levels of inflation that households perceive and the future inflation that they expect.

To evaluate the predictive power of perceived inflation, we regress households' inflation expectations on their perceived levels of inflation and their realized levels of inflation, both jointly and separately. Results are presented in Table 3. Each regressor is individually predictive of households' inflation expectations, i.e., the objective and subjective experiences of households are relevant in shaping their broader price expectations. At the same time, perceived inflation seems to explain a larger share of variation. When we add both jointly, each continues to remain statistically significant but the combined explanatory power is primarily explained by perceived rather than realized inflation. We interpret these results as indicating that while the objectively realized inflation for households is correlated with their subjective expectations of future aggregate inflation, one can obtain a stronger predictor of subjective expected inflation by eliciting households' subjective perceptions of past inflation. This evidence is consistent with the fact that households focus on specific goods when forming inflation perceptions and expectations rather than the subset of the overall bundle that we observe in the Nielsen panel (D’Acunto et al. 2021c,e). It is also consistent with the fact that households may use additional sources of information (beyond their own shopping experience) to form beliefs about broader economic conditions, such as information from family and friends, social media, and news media. 
Quantitatively, the rise in disagreement about perceived inflation can account for much of the dynamics in disagreement about expected inflation during the pandemic. The cross-sectional standard deviation of disagreement in expectations of future inflation rose by about 1 percentage point from 2020Q1 to 2020Q3-Q4, measured in point forecasts. The cross-sectional standard deviation of perceived inflation rose 1.0-1.5 percentage points over the same period. Given the coefficient of 0.45 linking the two from Table 2, this implies that disagreement about perceived inflation can account for about $50 \%$ of the rise in disagreement about future inflation during the COVID19 crisis.

\section{How Households Interpret the Driving Forces behind Inflation}

Belief about aggregate price changes are not formed in isolation. As argued in Kamdar (2018), households often seem to take a "supply-side" view of inflation in that their inflation expectations tend to be negatively correlated with their expectations of economic activity. Additional evidence for this view is proposed in Candia, Coibion and Gorodnichenko (2020), Coibion et al. (2020a) and Andre et al. (2021). As households experienced diverse sets of price changes during the pandemic, did they continue to interpret these through a supply-side lens or did their views about the origins of price changes change? Was it the case that disagreement about how to interpret the pandemic underlies the dramatically different inflation forecasts made by households during this period?

\subsection{Perceived and Expected Unemployment}

To investigate this topic, we utilize additional survey questions regarding the outlook for unemployment. Specifically, households were asked to provide point nowcasts for the current unemployment rate and forecasts of the unemployment rate in 12 months in most survey waves. The specific questions are

What is your best guess about what the current unemployment rate in the U.S. is, what it will be in 12 months?]

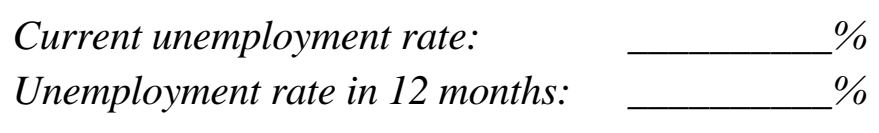

Similar to questions about perceived and expected inflation, questions about unemployment were rotating and some (randomly chosen) respondents were not asked these questions. Table 1 reports 
the number of respondents who reported their perceived and expected unemployment rates. Similar to the series for expected and perceived inflation expectations, we drop extreme observations (unemployment rate greater than 30 percent) and apply Huber weights to downplay outliers and influential observations.

Figure 9 plots the time series for means and standard deviations of perceived and expected unemployment rates. Consistent with official statistics, perceived and expected unemployment rates were trending down before the pandemic. In the second quarter of 2020, both perceptions and expectations shot up to double digits. Similar to inflation expectations and perceptions, the disagreement about current and future unemployment rose significantly during the early stages of the COVID19 crisis and gradually fell in subsequent quarters. Interestingly, although expected and perceived unemployment rates are highly correlated (Figure 10), expected unemployment rates in recent quarters are below perceived unemployment rates thus suggesting that households anticipate a (slow) recovery in the labor market.

\subsection{Expected Inflation vs Expected Unemployment}

Candia et al. (2020) document that professional forecasters predicted a negative comovement of inflation and unemployment during the COVID crisis, which is broadly consistent with a demanddriven recession and a downward-sloping Phillips curve. On the other hand, the dynamics in Figure 5 and Figure 9 suggest positive comovement between expected inflation and expected unemployment rate, which is consistent with a stagflationary, supply-side view. To explore further the robustness of this result for households, we plot a binscatter of households' unemployment forecasts versus their inflation forecasts both prior to the pandemic as well as during the pandemic (Figure 11). Before 2020, a clear positive relationship between the two existed: households who anticipated higher inflation also tended to anticipate higher unemployment. Strikingly, the relationship is almost identical during the COVID19 pandemic: except for those with very high unemployment forecasts, the two lines are nearly indistinguishable. Thus, the supply-side view taken by households of inflation remained unchanged during the pandemic, despite the unique nature of the crisis and all of the exceptional policy responses put in place during this period.

Furthermore, this supply-side view appears to be pervasive among households. For any subgroup that we consider, such as race, education, income, age or geography, the same qualitative pattern arises (Appendix Figure 6). While the relationship is stronger for some groups than others 
(e.g., Whites display the strongest correlation), it is present for all groups. This supply-side view is striking not just in how pervasive it is but also how different it is from the positive association that professional forecasters assume, as shown in Candia et al. (2020) and Kamdar (2018) or from the weak unconditional correlation between inflation and unemployment in U.S. data.

One implication is that the rising disagreement about future inflation observed during the pandemic cannot be explained by differing interpretations about the nature of the pandemic: those households who expected higher inflation were consistently the same households who expected a higher rate of unemployment. Differences in beliefs about the inflation and unemployment outlook were therefore likely a reflection of differences in beliefs about the severity of the shock, not about its nature. To support this point, we do the following exercise. First, for each household, we compute average expected inflation separately for the pre-pandemic period and for the pandemic period. We do the same calculation for the perceived inflation rate and for the expected unemployment rate. Second, we compute revisions in beliefs for each variable. Finally, we analyze the joint distribution of beliefs. ${ }^{10}$

Figure 12 presents a binscatter plot for the revision in expected inflation and expected unemployment and we report the corresponding regressions in Table 4. We observe a strong positive relationship between the revisions: a household who revised their inflation expectations up by one percentage point revised their unemployment expectations up by approximately 0.2 percentage points. Given the relatively short time difference between the measurements, it is unlikely that these revisions are driven by changes in demographics or other slow-moving characteristics of households. In agreement with this intuition, Table 4 documents that controlling for household characteristics does not materially affect the relationship between revisions for inflation expectations and revisions for unemployment expectations. Although this relationship is not causal, by using revisions that difference out household fixed effects, we likely attenuate endogeneity concerns that may plague causal interpretations of Figure 12.

To move closer to a causal interpretation of the relationship, we regress revisions for expected unemployment on revisions for expected inflation and instrument the latter with revisions for perceived inflation. As we discuss above, perceived inflation at the household level may be

\footnotetext{
${ }^{10}$ Because households may see different questions in different waves and may participate in different waves of the survey, taking averages across waves within each period helps us to maximize the sample size and to reduce noise in survey responses.
} 
moved by idiosyncratic shocks (e.g., a respondent happens to buy an expensive bottle of milk and concludes that aggregate inflation is high) and thus may provide suitable variation. To the extent this is indeed the case, perceived inflation can be used as an instrument for expected inflation. We find (columns 3 and 4 in Table 4) that, when we use instruments, the sensitivity of revisions for expected unemployment to revisions for expected inflation roughly triples from 0.17 to 0.45 . Thus, the positive relationship between unemployment and inflation in households' expectations is a robust phenomenon and households seem to have a stagflationary interpretation of the pandemic's macroeconomic implications.

\subsection{Discussion}

Similar to professional forecasters, policymakers predicted inflation to decline in response to the COVID19 crisis. To avoid potential deflation as well as a collapse of financial markets and the broader economy, aggressive monetary and fiscal stimulus programs were implemented. In part, the logic of these programs was to raise inflation expectations and hence stimulate consumer spending. However, our analysis suggests that such policies could be less effective than predicted by mainstream full-information rational expectations based models (D’Acunto et al. 2021f). Specifically, the pervasiveness of the supply-side view of inflation taken by households matters for the expected response of household spending to changes in inflation expectations: while the Euler equation implies that the anticipation of higher prices in the future should lead households to move their spending forward in time, a simultaneous expectation of a worsening economic outlook can instead lead them to curtail their spending. Indeed, evidence from information treatments that exogenously changed households' inflation expectations in the Netherlands (Coibion et al. 2019) and in the U.S. (Coibion, Gorodnichenko and Weber 2018) indicates that households respond to an increase in their inflation expectations by reducing their spending on durable goods sharply. Roth and Wohlfart (2020) also find that exogenously worsened economic outlooks lead households to reduce their planned spending. The positive relationship between inflation and unemployment in households' beliefs provides another mechanism to explain the severity of the reduction in spending during the pandemic: as inflation expectations rose due in part to households' experiences with higher prices, they expected a deeper slump and reduced their spending by more than they likely otherwise would have. Consistent with this logic, Coibion, 
Gorodnichenko and Weber (2020) find that marginal propensities to consume (MPCs) for stimulus payments during the pandemic were lower than MPCs for similar payments in previous recessions.

\section{Conclusion}

The pandemic recession of 2020 was unusual in many respects. One of these dimensions is that, as the level of economic activity plummeted starting March 2020, households' inflation expectations started to rise sharply at the same time as disagreement about future price dynamics spiked. We propose that a primary reason for this pervasive disagreement about the inflation outlook stems from the disparate consumer experiences with prices during this period. The early months of the pandemic were characterized by divergent price dynamics across sectors, leading to significant disparities in the inflation experiences of households. Perceptions of broader price movements diverged even more widely across households, leading them to draw very different inferences about the severity of the shock. These differences in perceived inflation changes were passed through not just into households' inflation outlooks but also their expectations of future unemployment. The widespread interpretation of the pandemic as a supply shock by households led those who perceived higher inflation during this period to anticipate both higher inflation and unemployment in subsequent periods.

While the magnitude of the rise in disagreement was notable, the supply side interpretation of the shock by households was not. Instead, it was consistent with a more systematic view taken by households that high inflation is associated with worse economic outcomes. This view is likely not innocuous for macroeconomic outcomes. Since policies like forward guidance are meant to operate in part by raising inflation expectations, this type of supply-side interpretation by households is likely to lead to weaker effects from these policies as households reduce, rather than increase, their purchases when anticipating future price increases.

This mechanism is also likely to be important during the inflation spike of 2021. As inflation expectations have been rising over the course of the year, households have been becoming more pessimistic about the economic outlook even as wages and employment have been rising sharply. This pessimism about the outlook creates a downside risk for the recovery and suggests that policymakers should be wary of removing supportive measures too rapidly. Patience in waiting for supply constraints to loosen therefore seems warranted since pre-emptive contractionary policies would likely amplify the pessimism that risks throttling the recovery from the pandemic. 


\section{References}

Andrade, Philippe, Erwan Gautier, and Eric Mengus, 2020. “What Matters in Households’ Inflation Expectations?” CEPR Working Paper 14905.

Andrade, Philippe, Olivier Coibion, Erwan Gautier, and Yuriy Gorodnichenko, 2020. "No Firm Is an Island? How Industry Conditions Shape Firms’ Expectations,” Journal of Monetary Economics (forthcoming).

Andre, Peter, Carlo Pizzinelli, Christopher Roth, and Johannes Wolhfart, 2021. “Subjective Models of the Macroeconomy: Evidence from Experts and Representative Samples,” manuscript.

Bachmann, Rudiger, Tim Berg and Eric Sims, 2015. "Inflation Expectations and Readiness to Spend: Cross-Sectional Evidence,” American Economic Journal: Economic Policy 7, 1-35.

Binder, Carola, 2017. “Fed Speak on Main Street: Central Bank Communication and Household Expectations,” Journal of Macroeconomics 52: 238-251.

Burke, Mary and Ali Ozdagli, 2021. "Household Inflation Expectations and Consumer Spending: Evidence from Panel Data,” forthcoming in The Review of Economics and Statistics.

Candia, Bernardo, Olivier Coibion, and Yuriy Gorodnichenko, 2020. “Communication and the Beliefs of Economic Agents,” NBER Working Paper 27800.

Cavallo, Alberto. 2020. “Inflation with Covid Consumption Baskets,” NBER Working Paper 27352.

Cavallo, Alberto, Guillermo Cruces, and Ricardo Perez-Truglia, 2017. "Inflation Expectations, Learning, and Supermarket Prices: Evidence from Survey Experiments,” American Economic Journal: Macroeconomics 9(3): 1-35.

Chahrour, Ryan, Kristoffer Nimark, and Stefan Pitschner, 2020. “Sectoral Media Focus and Aggregate Fluctuations,” Forthcoming in American Economic Review. 
Coibion, Olivier, Dimitris Georgarakos, Yuriy Gorodnichenko, and Maarten van Rooij, 2019. "How Does Consumption Respond to News About Inflation? Field Evidence from a Randomized Control Trial,” American Economic Journal - Macroeconomics (forthcoming).

Coibion, Olivier, Dimitris Georgarakos, Yuriy Gorodnichenko, and Michael Weber, 2020a. “Forward Guidance and Household Expectations” NBER Working Paper 26778.

Coibion, Olivier, and Yuriy Gorodnichenko. 2015. "Is the Phillips Curve Alive and Well after All? Inflation Expectations and the Missing Disinflation.” American Economic Journal: Macroeconomics 7(1): 197-232.

Coibion, Olivier, Yuriy Gorodnichenko, and Gee Hee Hong. 2015. "The Cyclicality of Sales, Regular and Effective Prices: Business Cycle and Policy Implications.” American Economic Review 105 (3): 993-1029.

Coibion, Olivier, Yuriy Gorodnichenko, and Dmitri Koustas, 2021. “Consumption Inequality and the Frequency of Purchases,” American Economic Journal: Macroeconomics 13(4): 449-82.

Coibion, Olivier, Yuriy Gorodnichenko, and Michael Weber, 2018. "Monetary Policy Communications and their Effects on Household Inflation Expectations,” Journal of Political Economy (forthcoming).

Coibion, Olivier, Yuriy Gorodnichenko, and Michael Weber, 2020. “How Did U.S. Consumers Use Their Stimulus Payments?” NBER Working Paper 27693.

Coibion, Olivier, Yuriy Gorodnichenko, and Michael Weber, 2021. "Fiscal Policy and Households’ Inflation Expectations: Evidence from a Randomized Control Trial,” NBER Working Paper 28485.

Coibion, Olivier, Yuriy Gorodnichenko, and Rupal Kamdar, 2018. “The Formation of Expectations, Inflation and the Phillips Curve,” Journal of Economic Literature 56: 1447-91. 
Coibion, Olivier, Yuriy Gorodnichenko, Saten Kumar, and Mathieu Pedemonte, 2020. "Inflation Expectations as a Policy Tool?” Journal of International Economics 124: 103297.

Crump, Richard K., Stefano Eusepi, Andrea Tambalotti, and Giorgio Topa, 2015. "Subjective Intertemporal Substitution,” Journal of Monetary Economics (forthcoming).

D’Acunto, Francesco, Daniel Hoang, Maritta Paloviita, and Michael Weber, 2021a. “IQ, Expectations, and Choice,” Review of Economic Studies (forthcoming).

D’Acunto, Francesco, Daniel Hoang, Maritta Paloviita, and Michael Weber, 2021f. "Human Frictions in the Transmission of Economic Policies,” NBER Working Paper 29279.

D’Acunto, Francesco, Daniel Hoang, and Michael Weber, 2021b. “Managing Household Expectations with Unconventional Policies,” Review of Financial Studies (forthcoming).

D’Acunto, Francesco, Ulrike Malmendier, and Michael Weber, 2021c. "Gender roles produce divergent economic expectations,” Proceedings of the National Academy of Sciences 118(21): 1-10.

D’Acunto, Francesco, Ulrike Malmendier, and Michael Weber, 2021d. “Inflation Expectations,” in: Handbook of Subjective Expectations (forthcoming).

D’Acunto, Francesco, Ulrike Malmendier, Juan Ospina, and Michael Weber, 2021e. “Exposure to Grocery Prices and Inflation Expectations,” Journal of Political Economy 129(5): 1615-1639.

Eichenbaum, Martin S., Sergio Rebelo and Mathias Trabandt, 2021. "The Macroeconomics of Epidemics,” NBER Working Paper 26882.

Gautier, Erwan, Youssef Ulgazi, and Paul Vertier, 2020. “Inflation and Households’ Inflation Expectations During the COVID-19 Pandemic,” Banque De France, Eco Notepad \#171, https://blocnotesdeleco.banque-france.fr/en/blog-entry/inflation-and-households-inflationexpectations-during-covid-19-pandemic. 
Jaimovich, Nir, Sergio Rebelo, and Arlene Wong, 2019. “Trading down and the business cycle,” Journal of Monetary Economics 102(C): 96-121.

Jaravel, Xavier, 2021. "Inflation Inequality: Measurement, Causes, and Policy Implications.” forthcoming in Annual Review of Economics.

Jonung, Lars, 1981 “Perceived and Expected Rates of Inflation in Sweden,” American Economic Review 71(5): 961-968.

Kamdar, Rupal, 2018. “The Inattentive Consumer: Sentiment and Expectations,” Manuscript. Kaplan, Greg, and Sam Schulhofer-Wohl, 2017. "Inflation at the household level," Journal of Monetary Economics 91(C): 19-38.

Kumar, Saten, Hassan Afrouzi, Olivier Coibion, and Yuriy Gorodnichenko, 2015. "Inflation Targeting Does Not Anchor Inflation Expectations: Evidence from Firms in New Zealand," Brookings Papers on Economic Activity 46(2 (Fall)): 151-225.

Lamla, Michael J., and Dmitri V. Vinogradov, 2019. “Central bank announcements: Big news for little people?” Journal of Monetary Economics 108(C): 21-38.

Lucas, Robert, 1972. “Expectations and the Neutrality of Money,” Journal of Economic Theory 4(2): 103-124.

Mankiw, N. Gregory, Ricardo Reis, and Justin Wolfers, 2003. "Disagreement about Inflation Expectations,” NBER Macroeconomics Annual, 18, 209-270.

Reis, Ricardo, 2020. "Comment on "Imperfect Macroeconomic Expectations: Yes, But We Disagree.” NBER Macroeconomics Annual 2020, forthcoming.

Reis, Ricardo, 2021. "Losing the inflation anchor." Brookings Papers on Economic Activity (forthcoming). 
Roth, Christopher, and Johannes Wohlfart. 2020. “How Do Expectations about the Macroeconomy Affect Personal Expectations and Behavior?” Review of Economics and Statistics 102 (4): $731-748$.

Weber, Michael, Francesco D’Acunto, Yuriy Gorodnichenko, and Olivier Coibion, 2021. “Reality Check: How People Form Inflation Expectations and Why You Should Care,” manuscript. 
Figure 1. Realized Inflation of U.S. Households.

\section{Panel A: Mean and Dispersion of Realized Inflation}

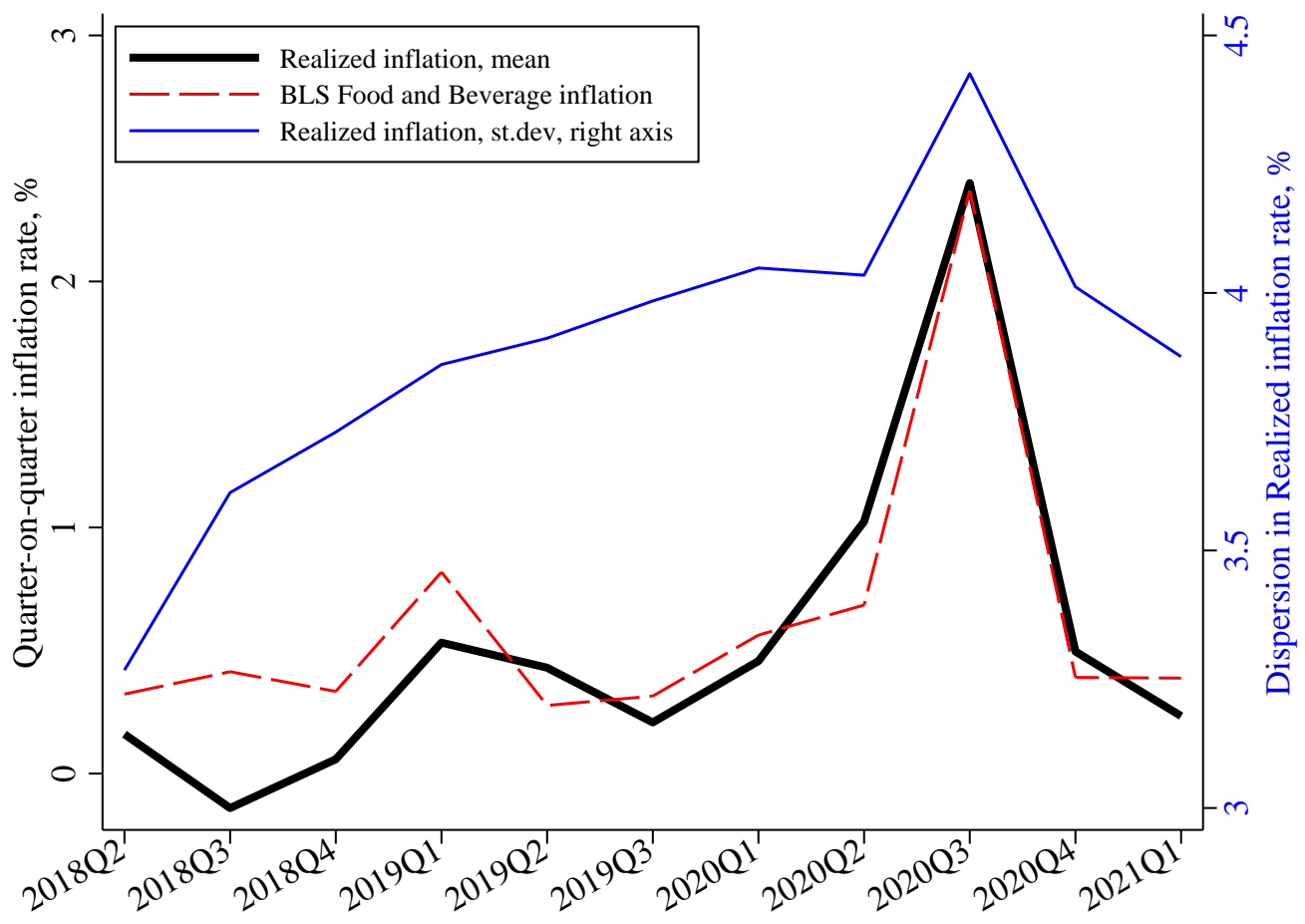

\section{Panel B: Distribution of Realized Inflation}

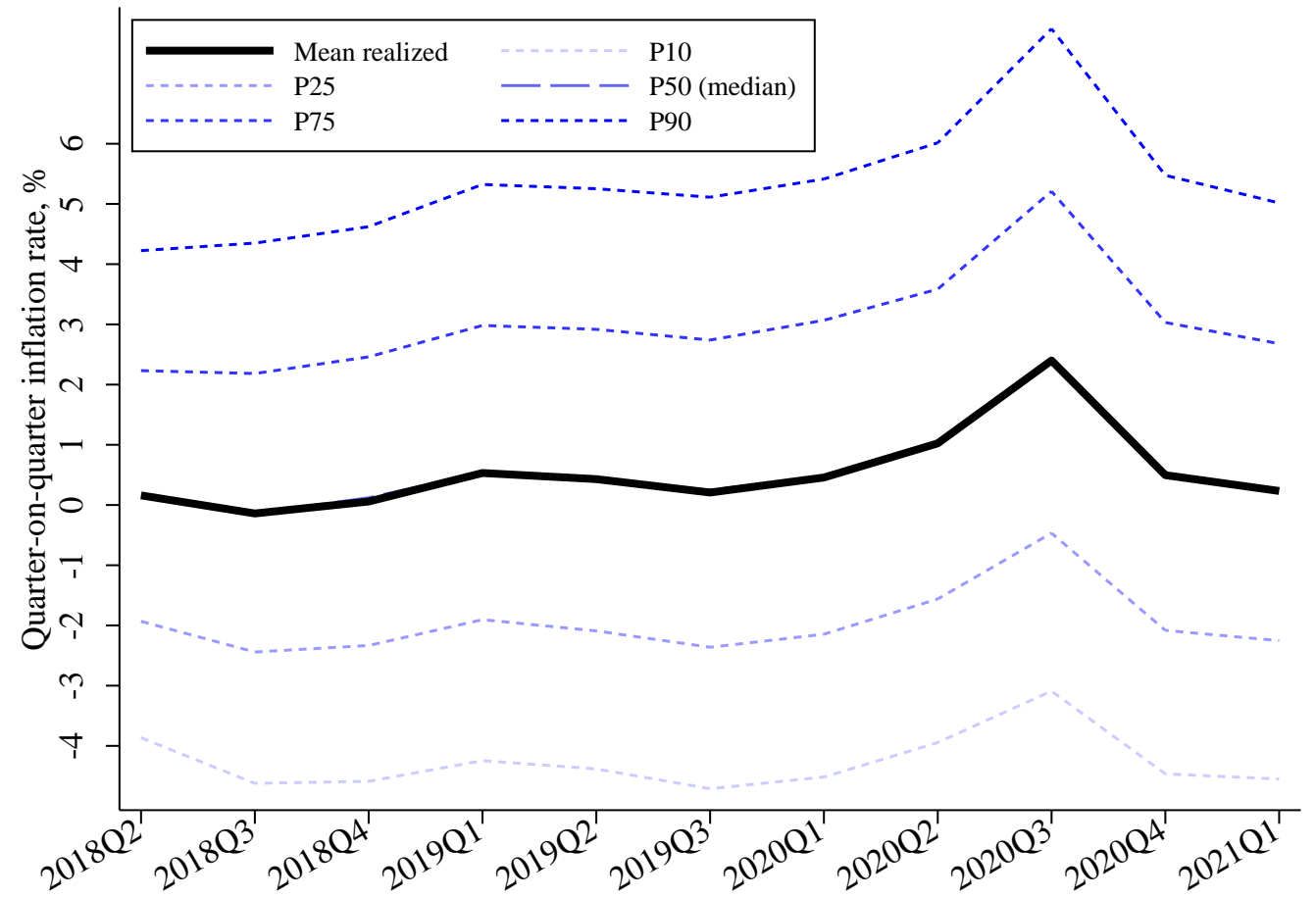

Notes: the top panel plots time series of food inflation rate reported by the Bureau of Labor Statistics and average (across households) inflation rated computed for prices reported in the Nielsen Homescan Panel ("realized inflation"). This panel also shows the time series of cross-sectional dispersion for realized inflation. The bottom panel reports the time series for percentiles of inflation realized by households in the Nielsen Homescan Panel. 
Figure 2. Realized Inflation by Subgroups of Households.

Panel A. By race

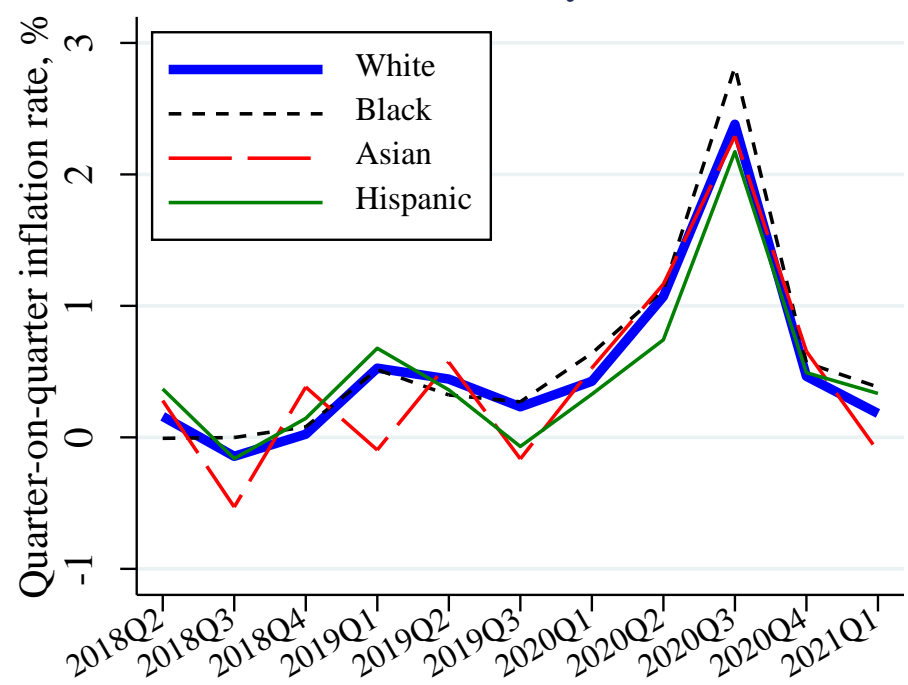

Panel C. By education

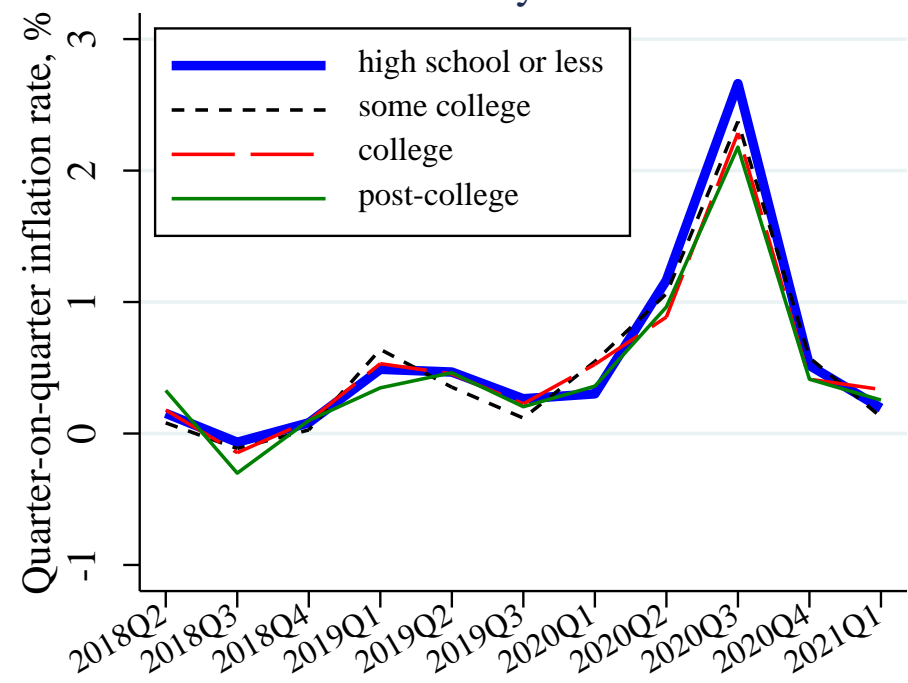

Panel B. By income

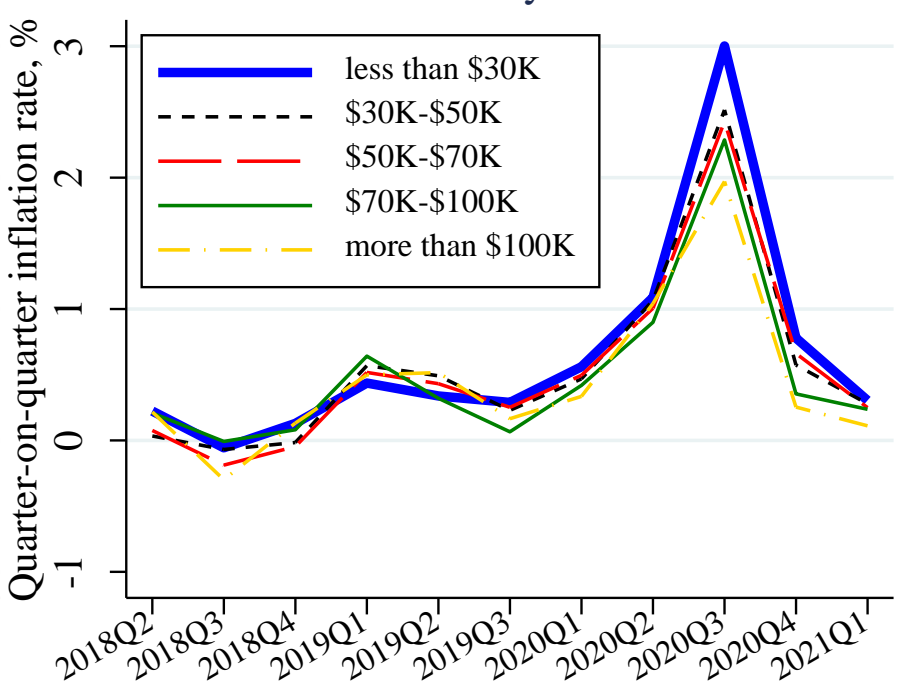

Panel D. By region

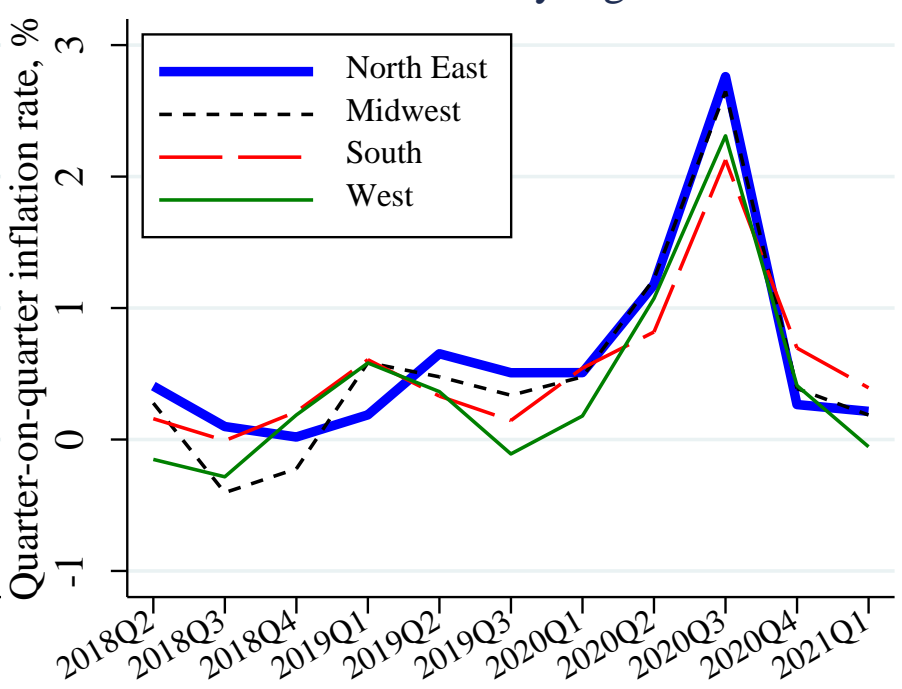

Notes: the figure plots time series of inflation rate realized by various groups of households in the Nielsen Homescan Panel. 
Figure 3. Realized Inflation by Types of Goods.

Panel A: Dispersion of Inflation Rates across Goods

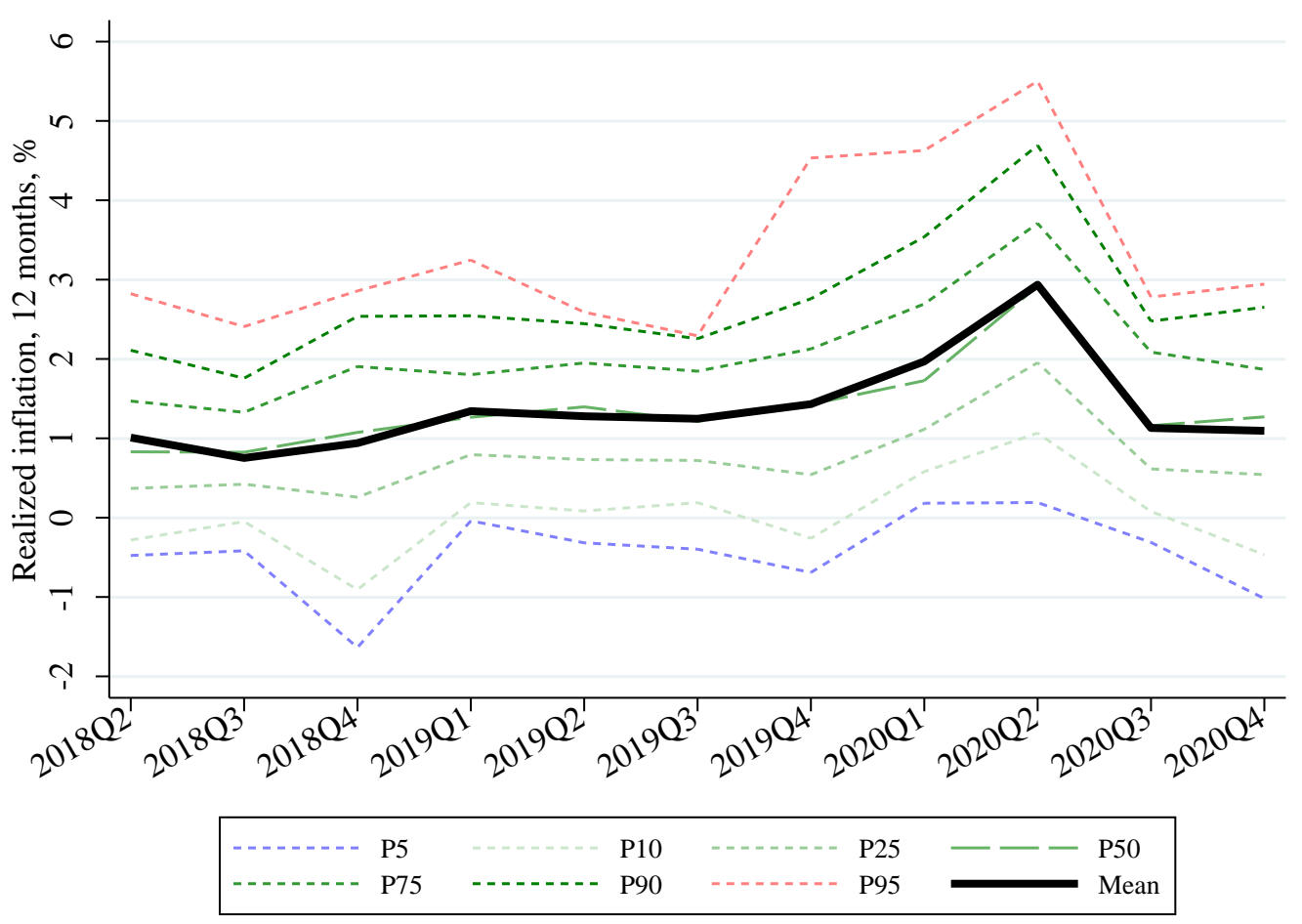

\section{Panel B: Inflation Rates of Select Categories of Goods}

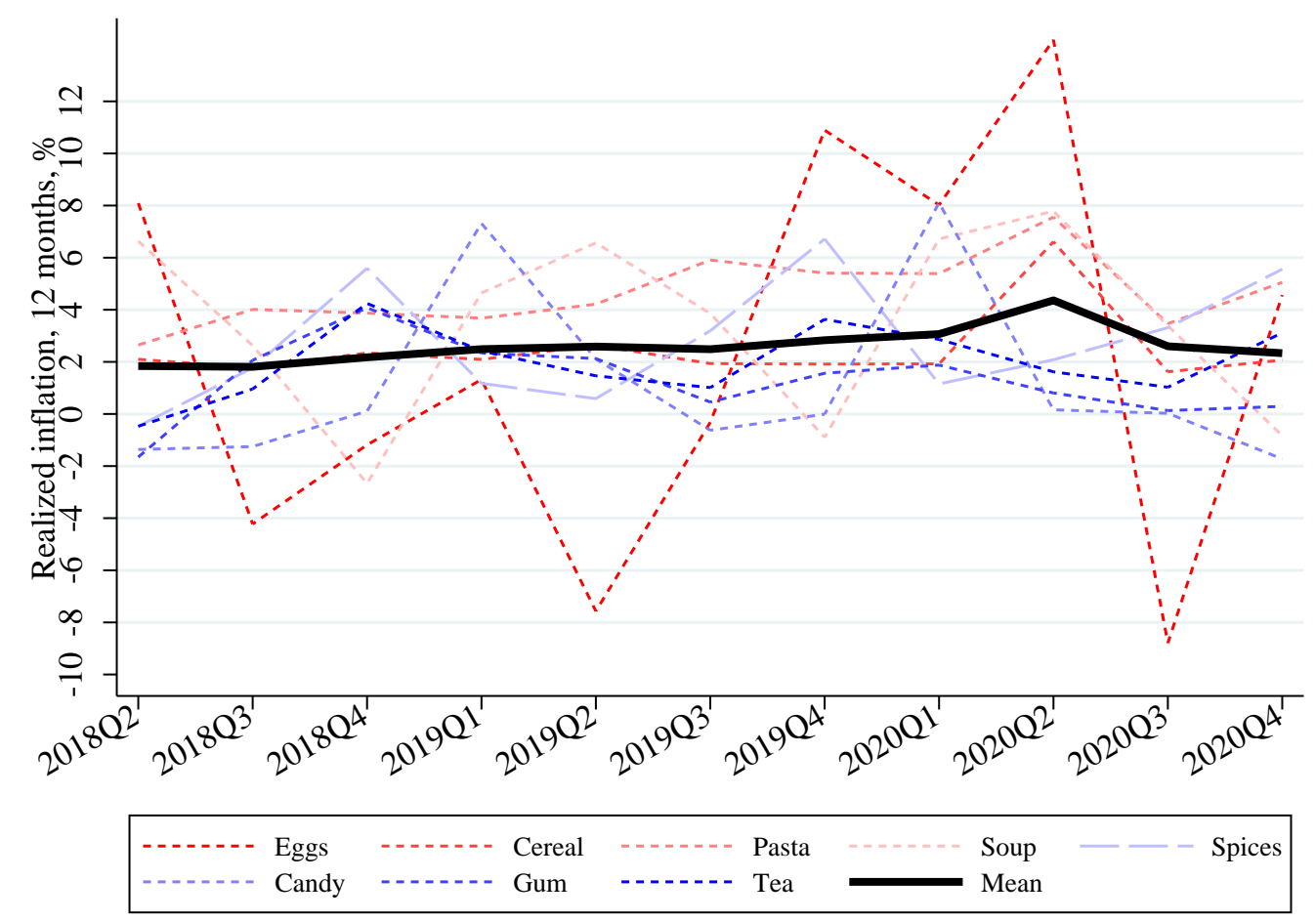

Notes: The top panel shows times series for percentiles of inflation rates (average across households) across product groups in the Nielsen Homescan Panel. The bottom panel shows time series of inflation rates (average across households) for select product groups in the Nielsen Homescan Panel. 
Figure 4. Across-household within-product-group dispersion of realized inflation rates.

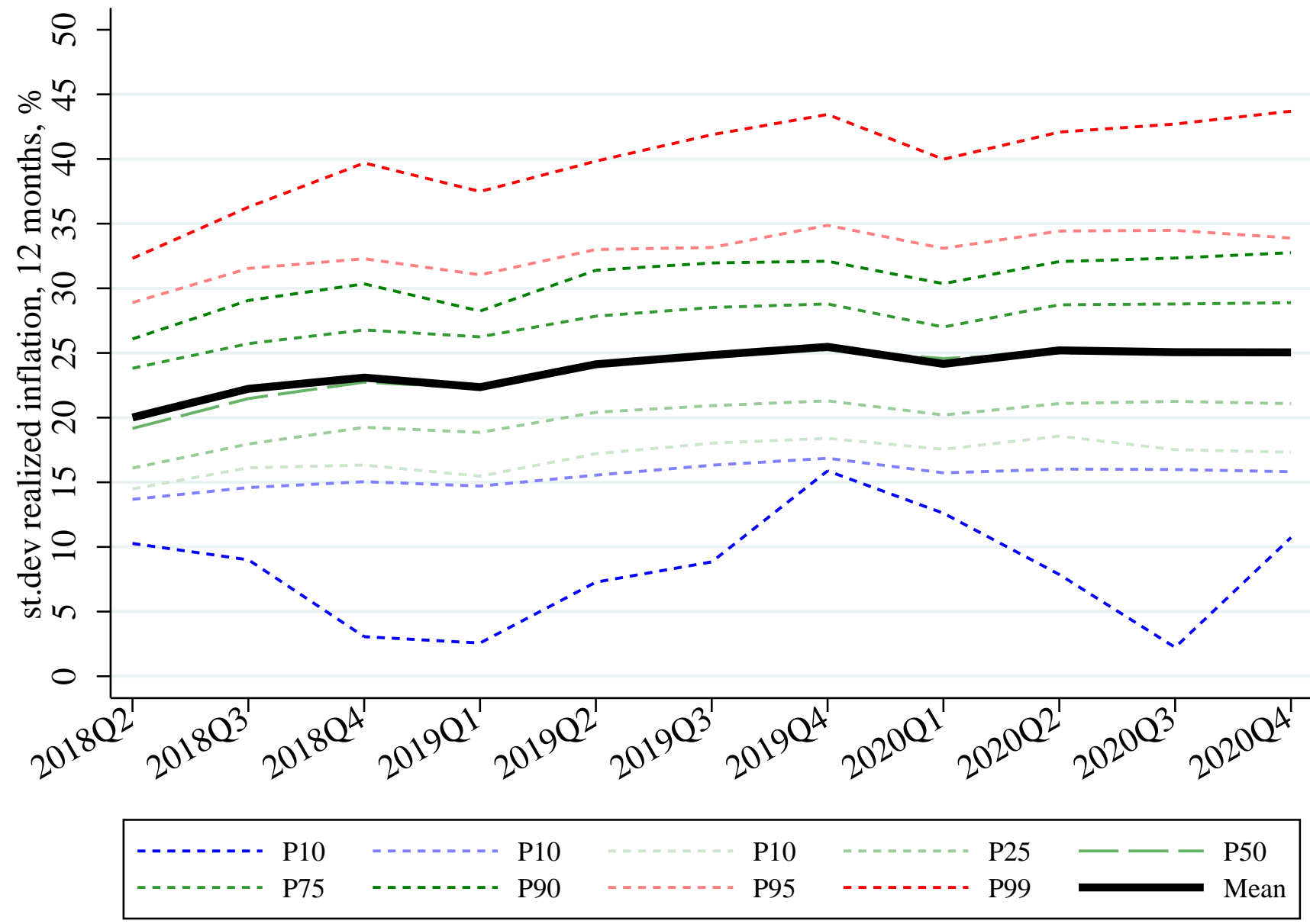

Notes: The figure shows dispersion of within-product-module inflation rates realized by households in the Nielsen Homescan Panel 
Figure 5. Expected Inflation of U.S. Households

\section{Panel A: Expected Inflation from Point Forecasts}

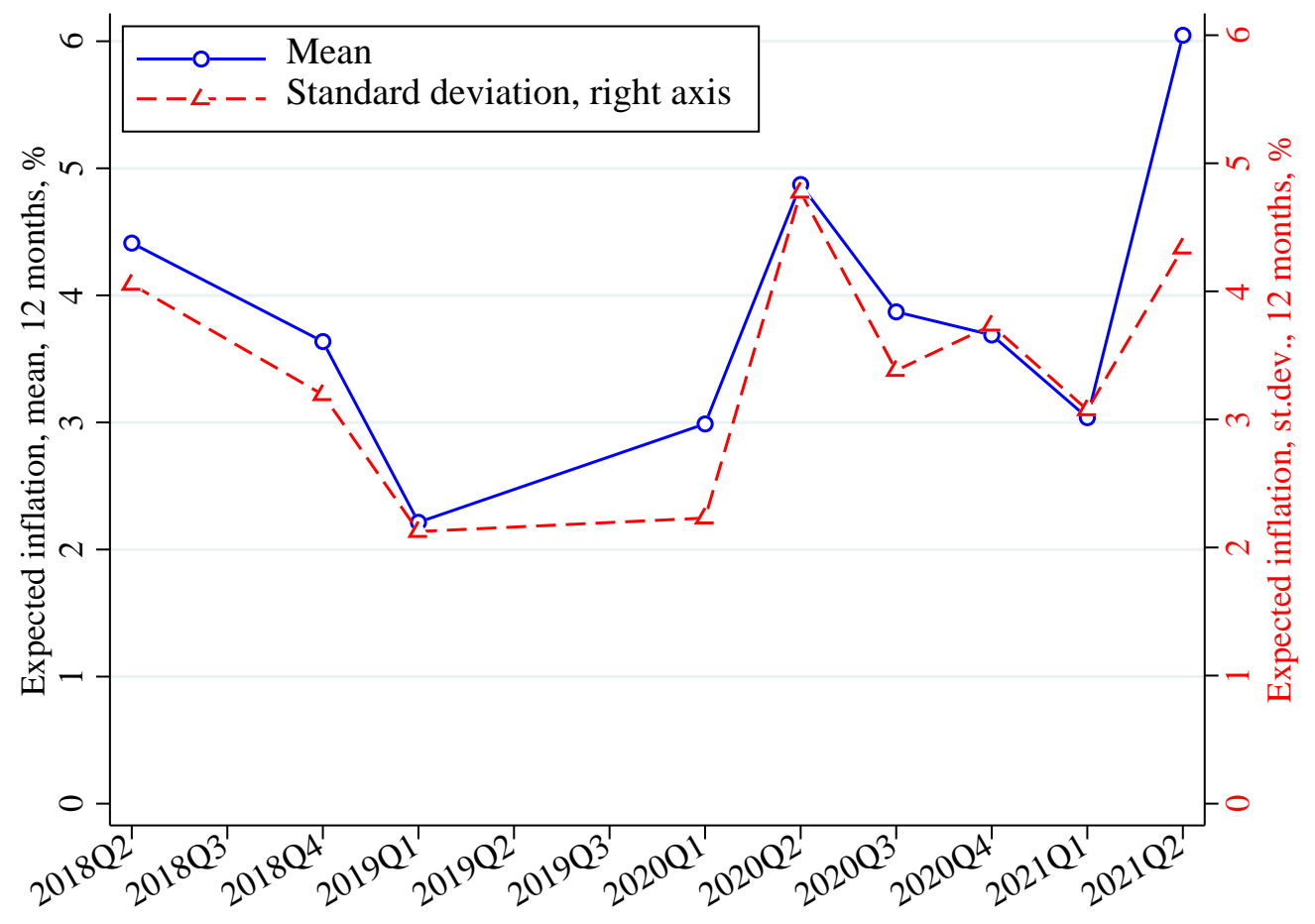

Panel B: Expected Inflation from Implied Means

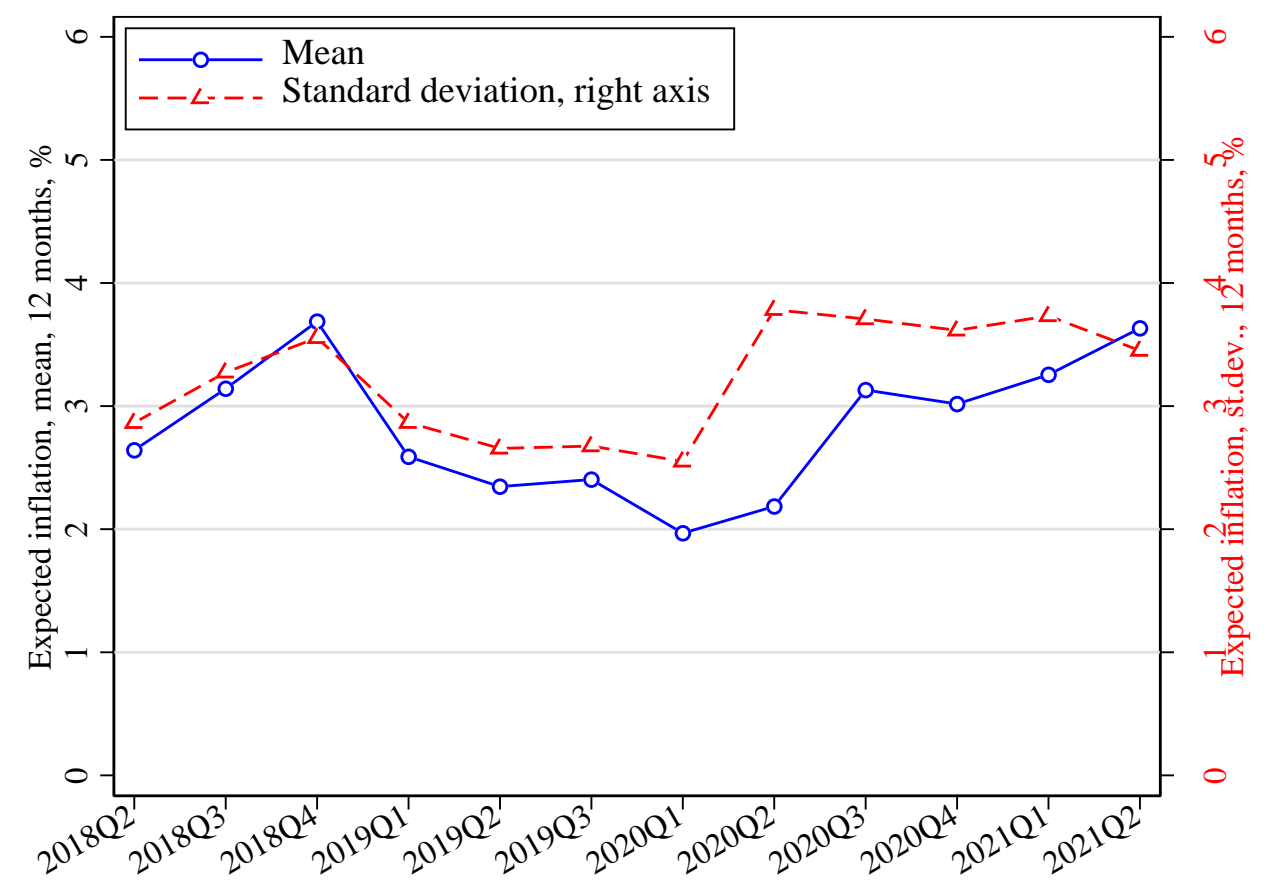

Notes: The figure plots Huber estimates of the mean and cross-sectional standard deviation of survey respondents' expected inflation over the next 12 months based on questions asking for a point forecast (Panel A) or implied means from distributional questions (Panel B). 
Figure 6. Realized and Expected Inflation of U.S. Households.

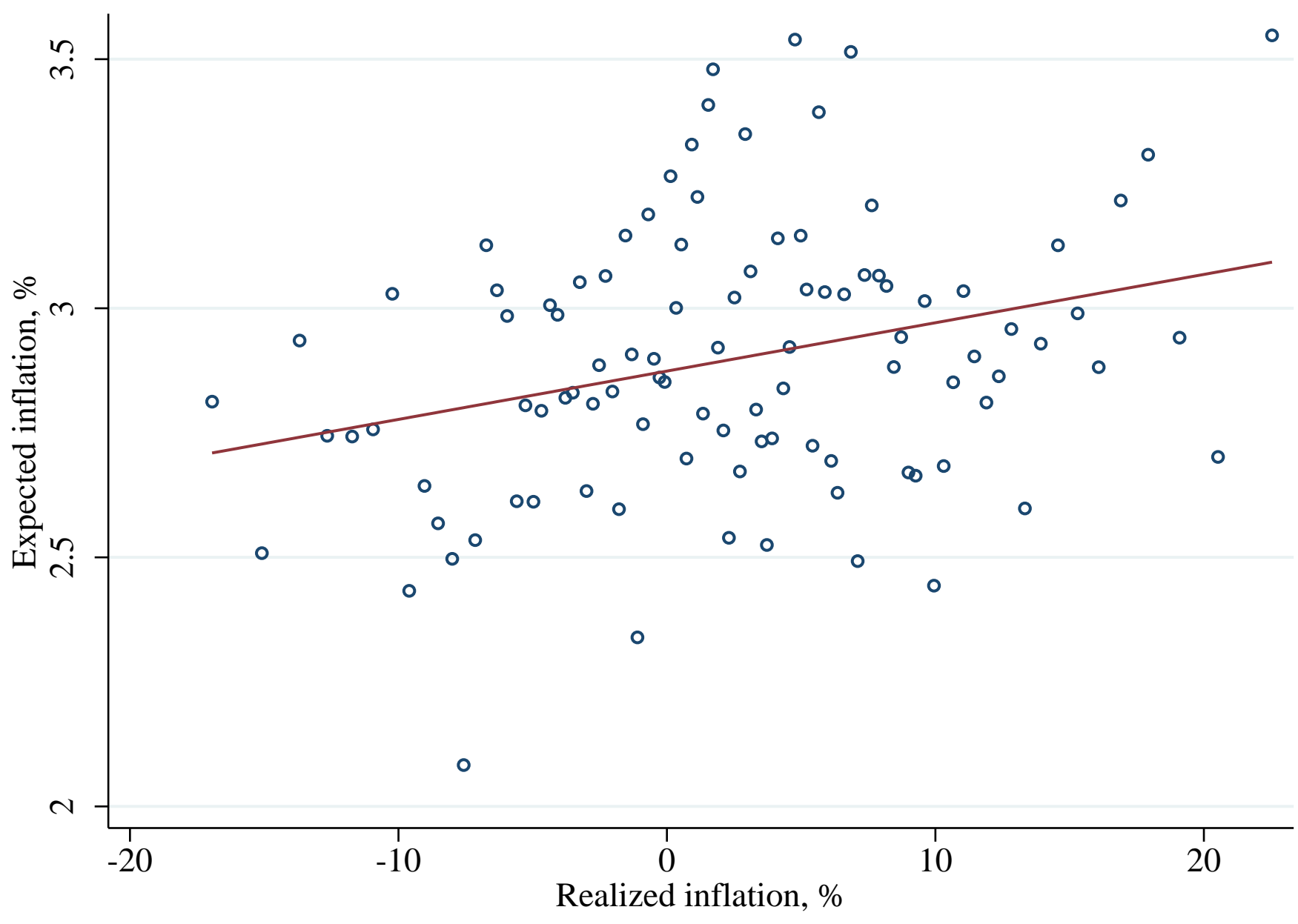

Notes: The figure shows binscatters of realized inflation (x-axis) in the Nielsen Homescan Panel and expected inflation (y-axis; implied mean) in the survey. 

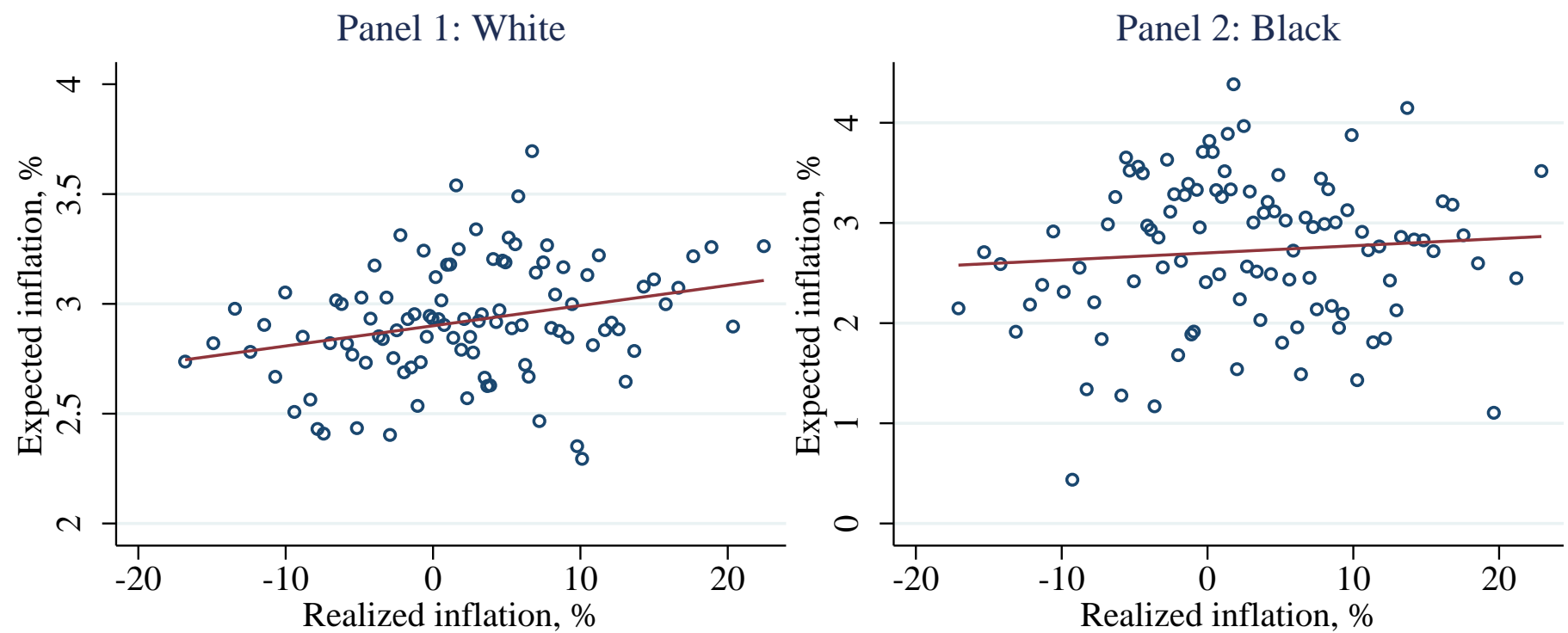

Panel 3: Asian

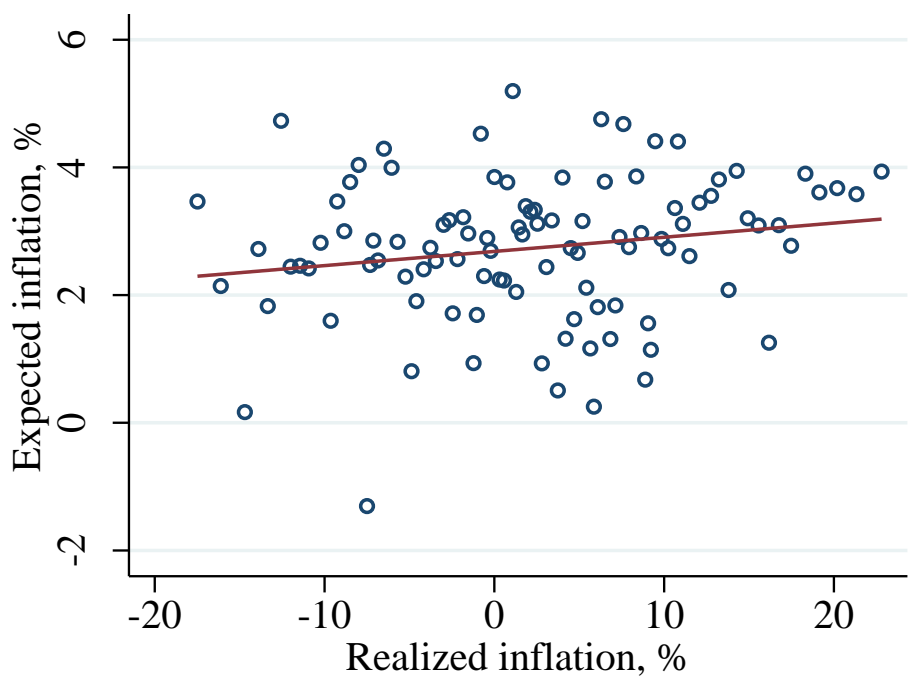

Panel 4: Hispanic

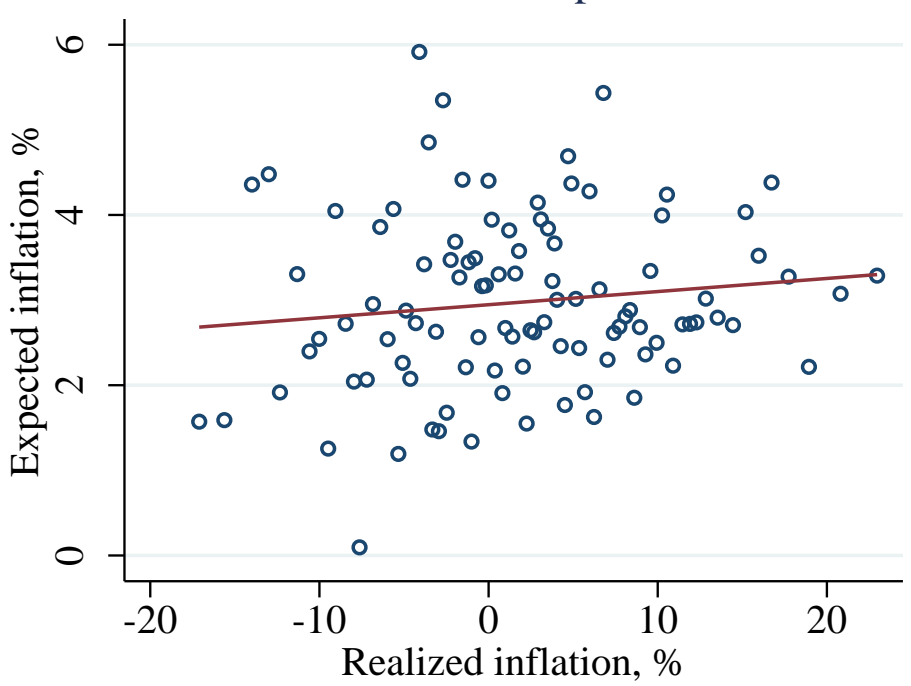

Notes: The figure shows binscatters of experienced inflation (x-axis) in the Nielsen Homescan Panel and expected inflation (y-axis; implied mean) in the survey for various demographic groups. 
Figure 8. Perceived Inflation of U.S. Households

Panel A: Perceived Inflation over Time

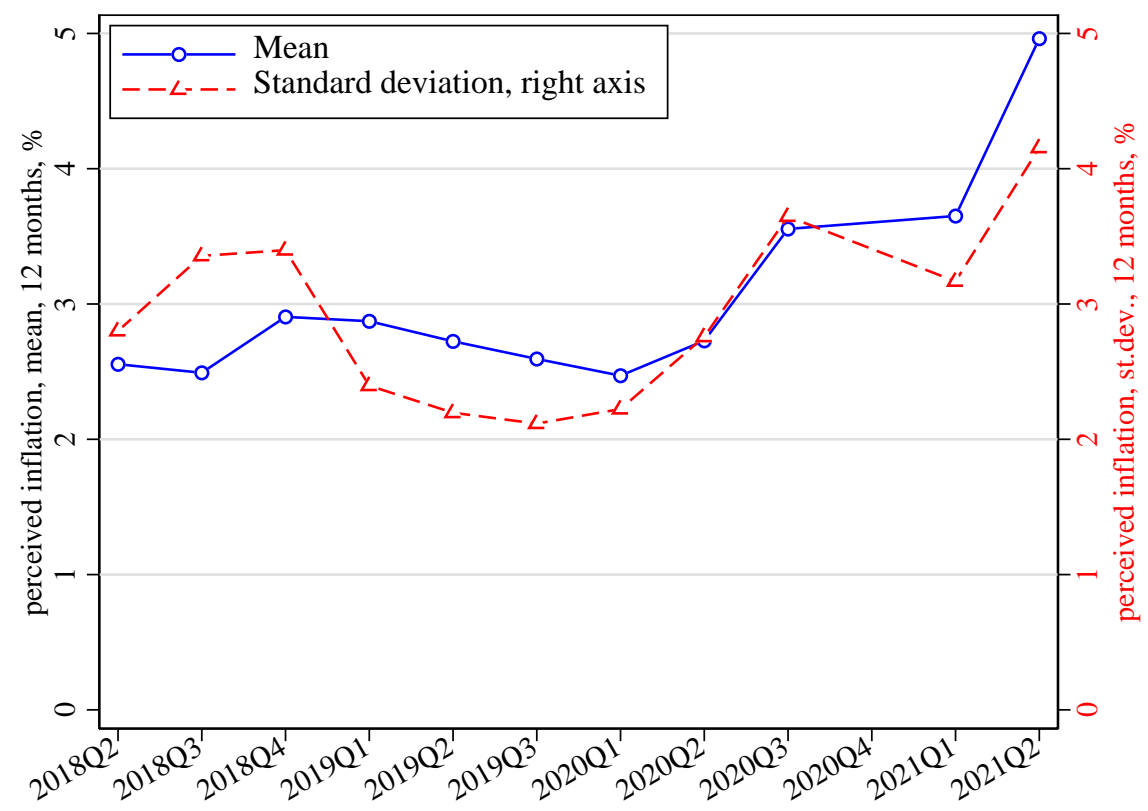

$\underline{\text { Panel B: Cross-Sectional Correlation between Perceived and Expected Inflation }}$

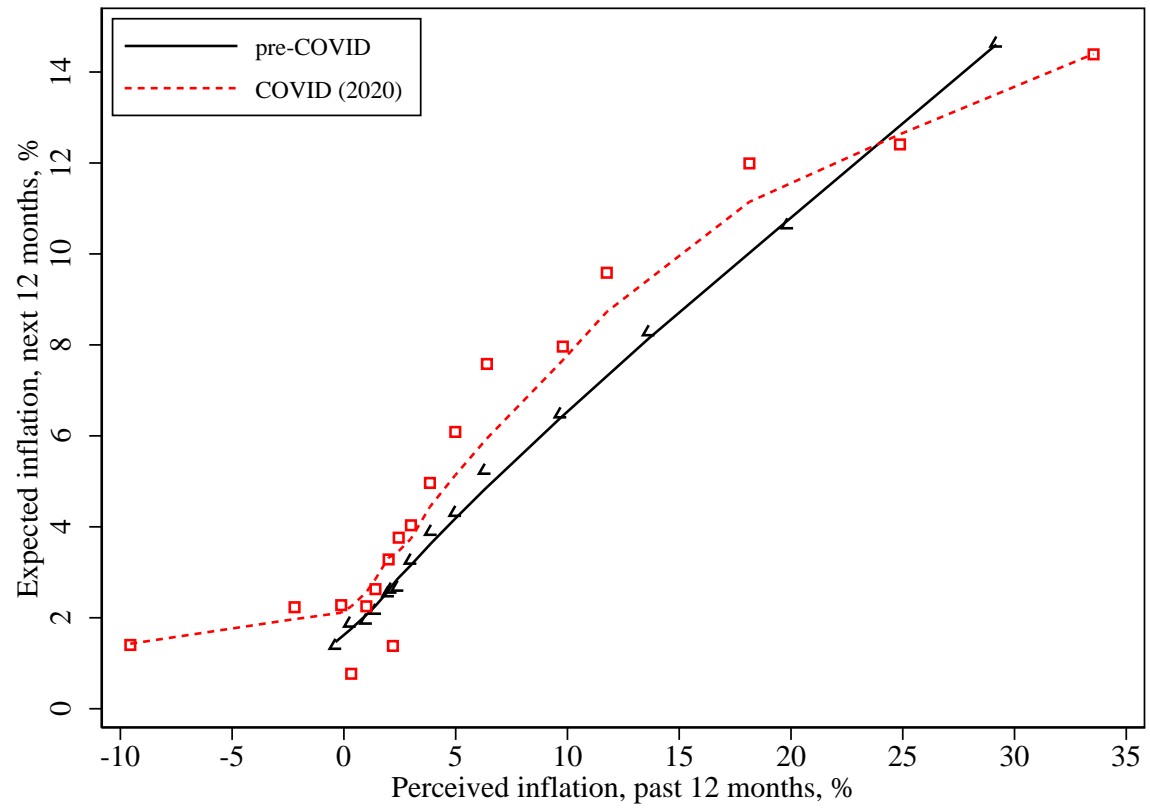

Notes: The top panel plots the time series of the Huber-robust mean of perceived inflation by U.S. households as well as the time series of the cross-sectional standard deviation in perceived inflation. The bottom panel plots a binscatter of households' perceived level of inflation over the last 12 months (x-axis) versus their expected level of inflation (point prediction) over the next 12 months (y-axis) in the pre-COVID19 sample (black triangles) as well as the COVID19 sample (red squares). 
Figure 9. Perceived and expected unemployment rate.

Panel A. Expected unemployment rate.

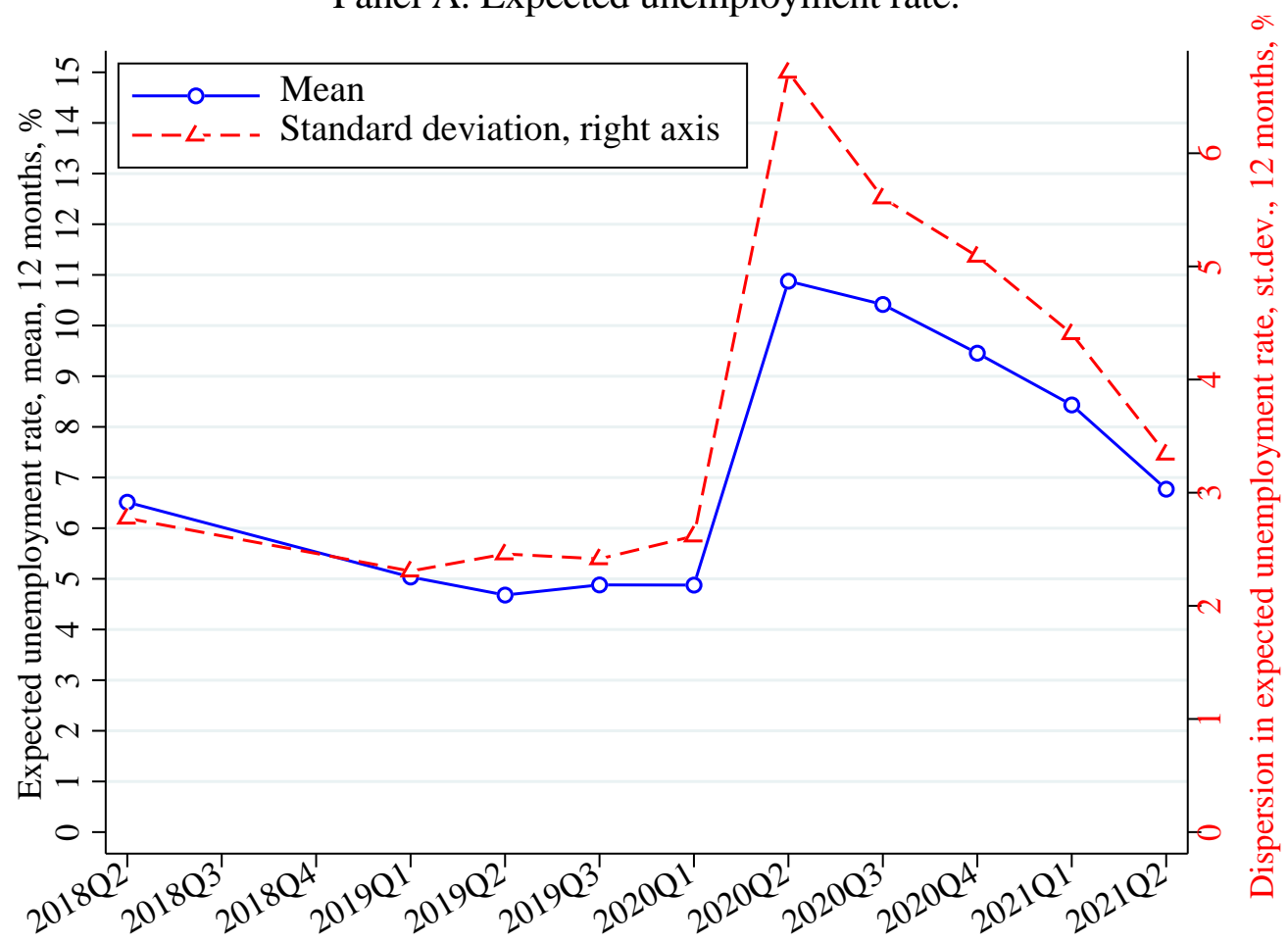

Panel B. Perceived unemployment rate.

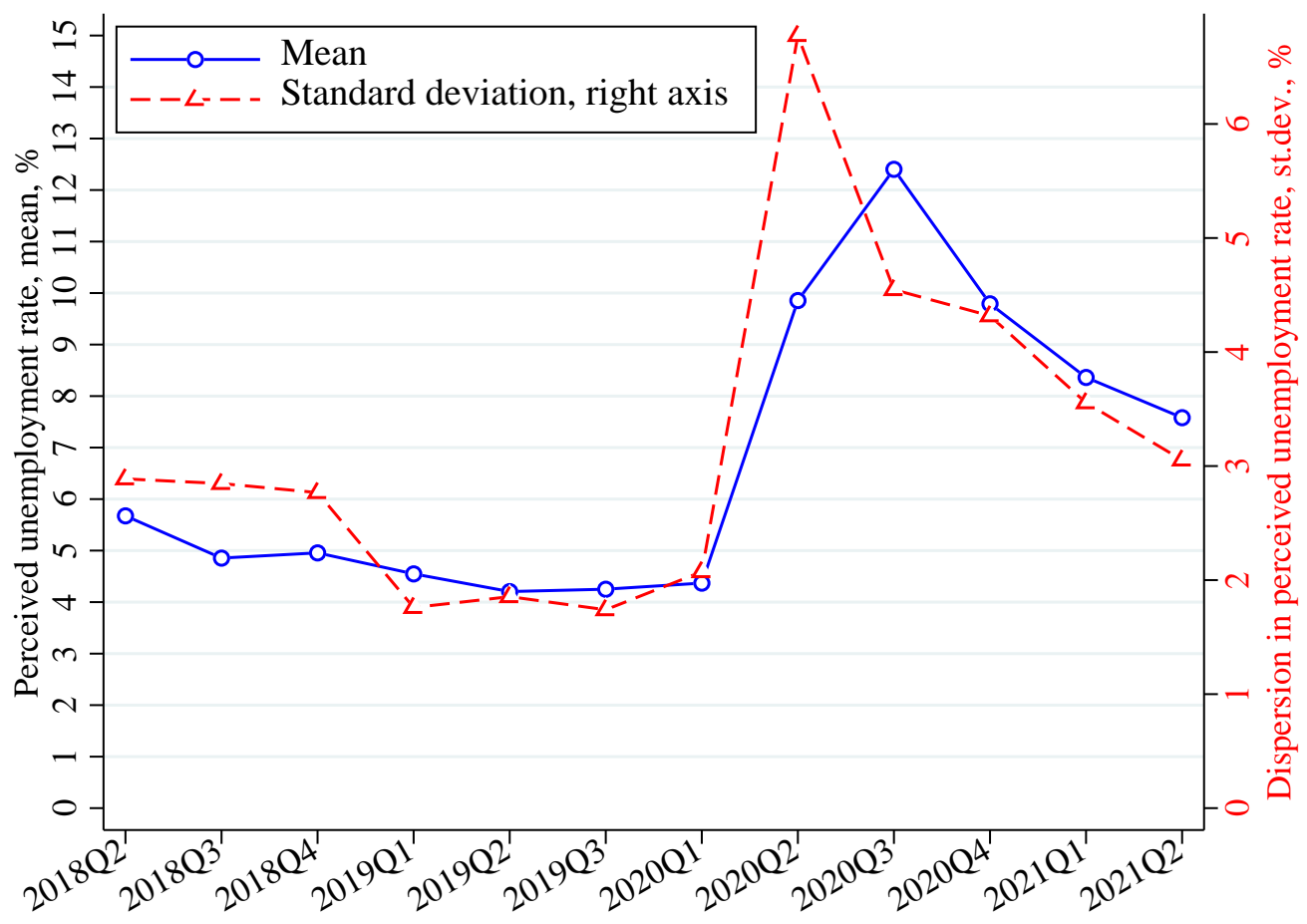

Notes: The figure plots Huber estimates of the mean and cross-sectional standard deviation of survey respondents' expected unemployment rate over the next 12 months (Panel A) or perceptions of current unemployment rate (Panel B). 
Figure 10. Perceived vs. expected unemployment rate.

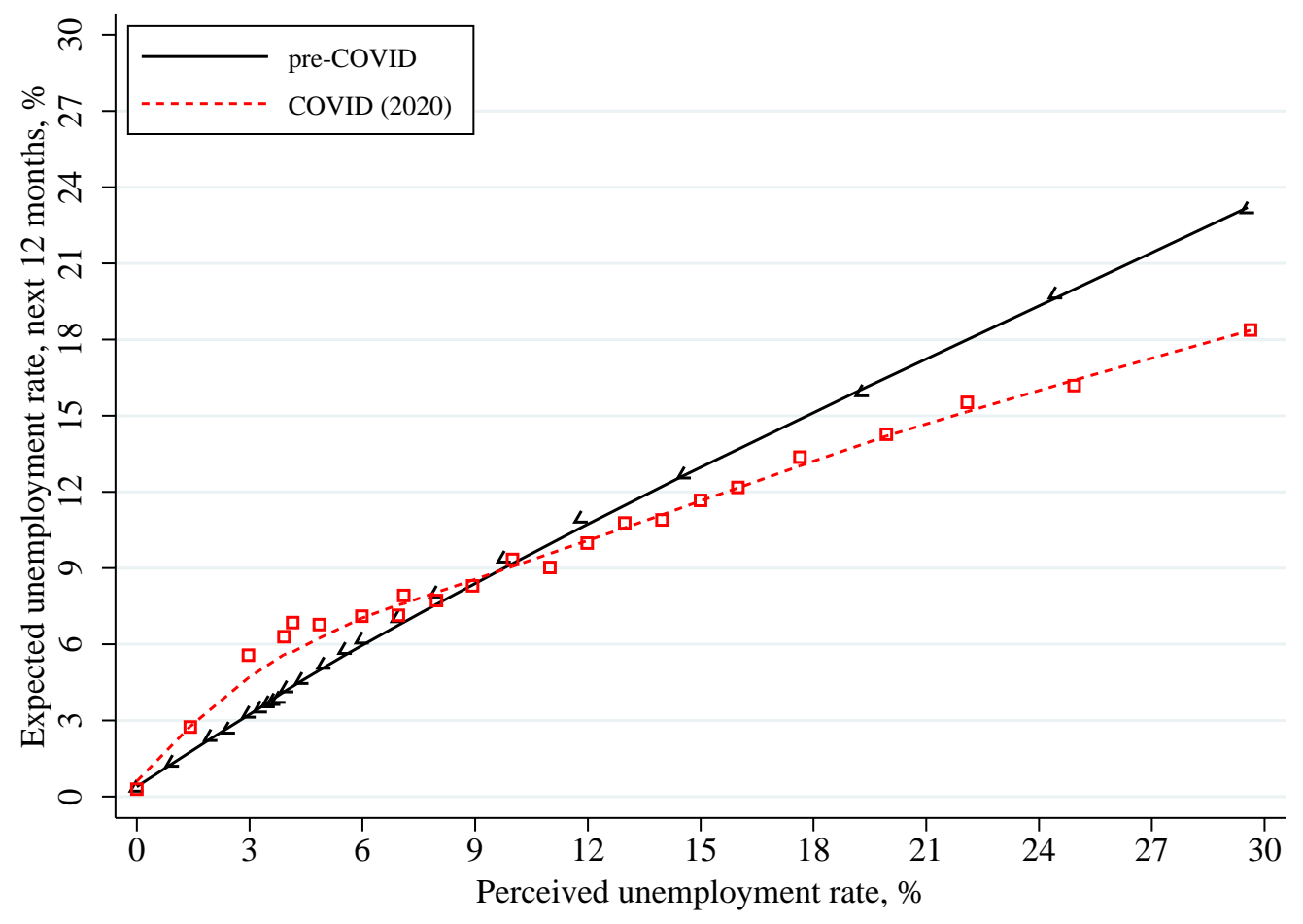

Notes: the figure shows binscatter plots of perceived vs. expected unemployment rate in the pre-COVID period and in the COVID19 period. 
Figure 11. Unemployment and Inflation Expectations.

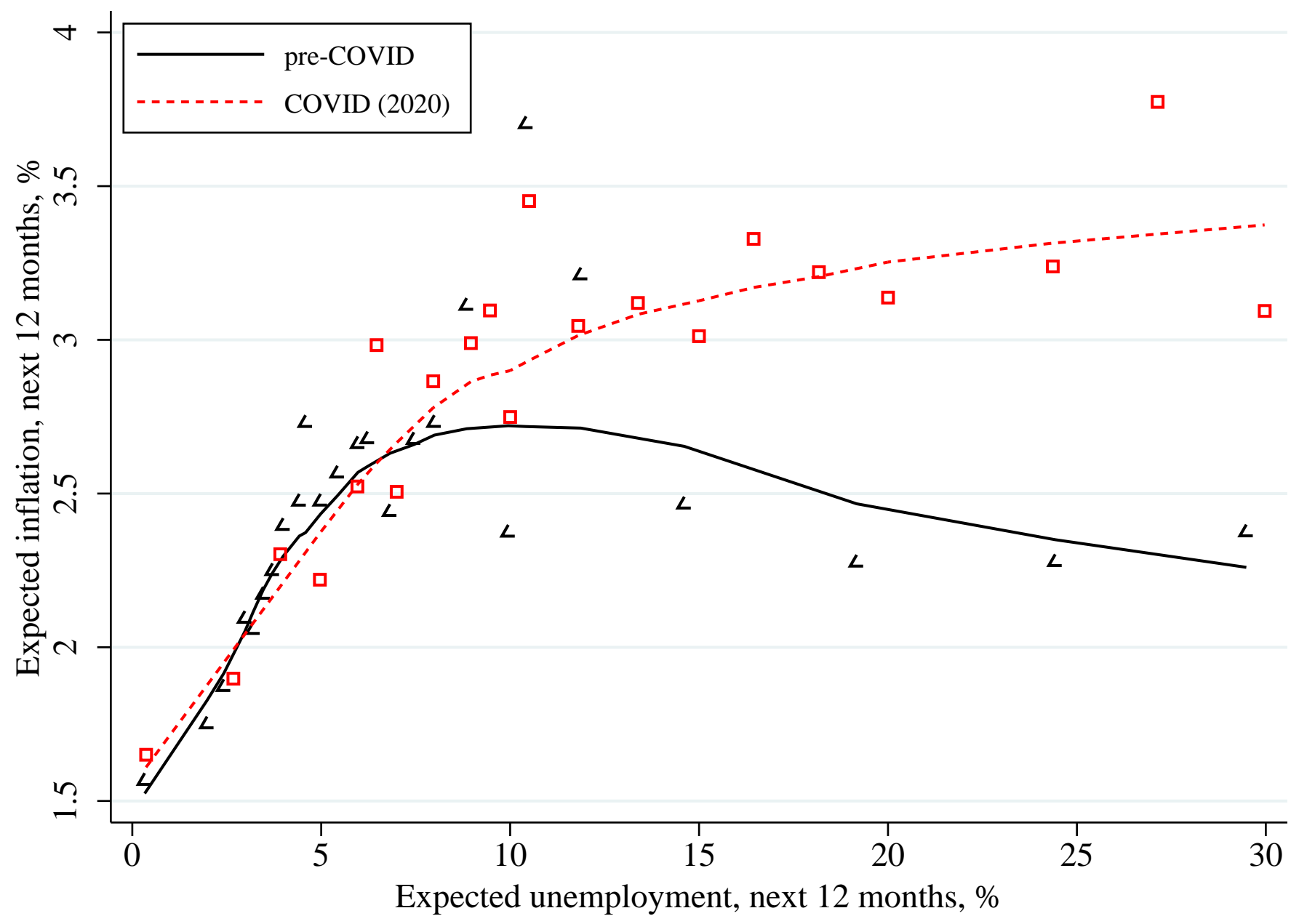

Notes: The figure shows a binscatter of expected inflation (y-axis; implied mean) and expected unemployment (x-axis) in the survey. 
Figure 12. Revisions in expected inflation and unemployment rates.

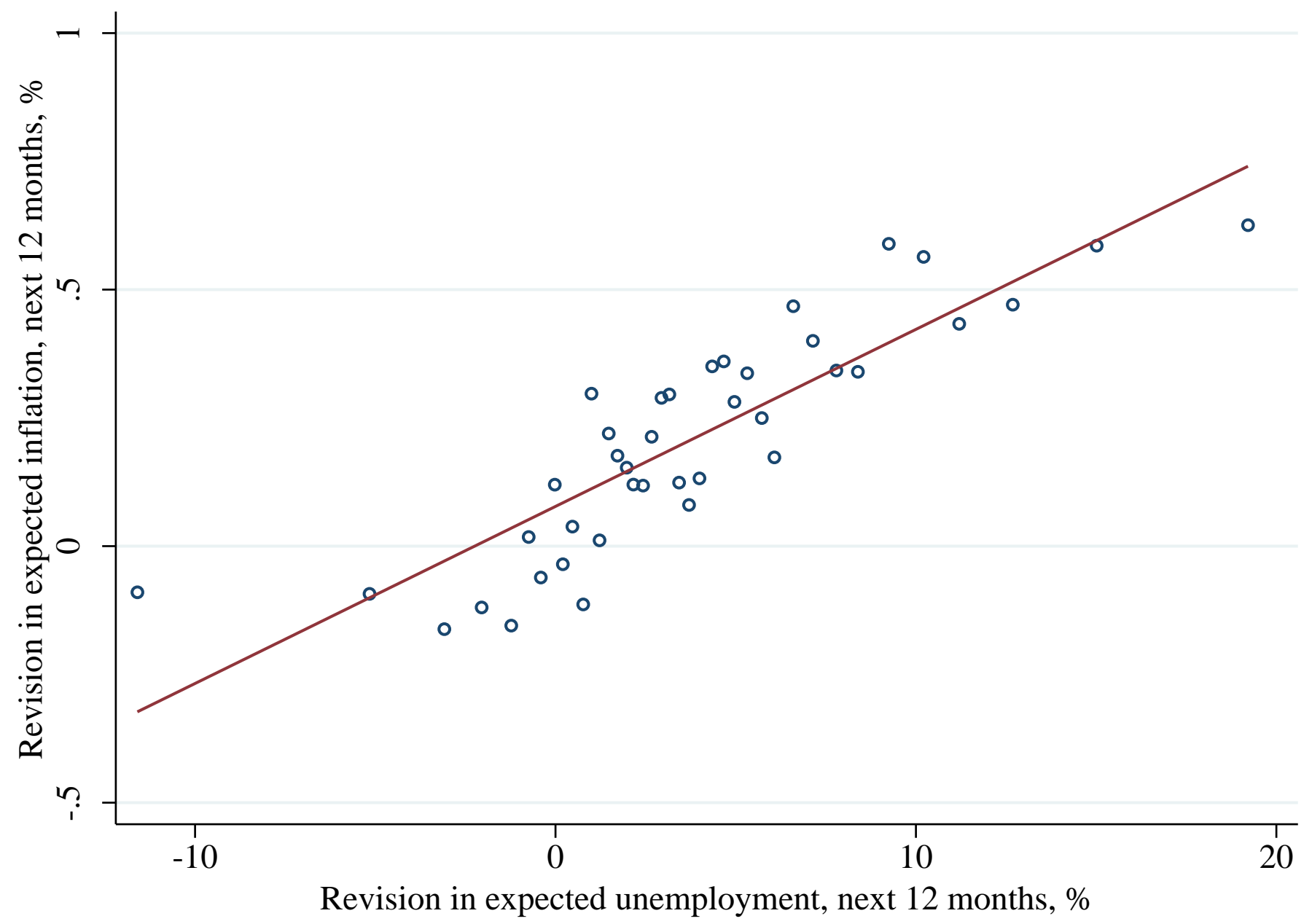

Notes: The figure shows a binscatter of revisions in expected inflation (y-axis; implied mean) vs revisions in expected unemployment (xaxis) in the survey. 
Table 1. Number of Observations of Perceived and Expected Inflation.

\begin{tabular}{|c|c|c|c|c|c|c|c|c|}
\hline \multirow{2}{*}{\multicolumn{2}{|c|}{ Wave }} & \multicolumn{4}{|c|}{ Inflation rate } & \multicolumn{3}{|c|}{ Unemployment rate (UR) } \\
\hline & & \multirow{2}{*}{$\begin{array}{c}\text { Expected } \\
\text { inflation, } \\
\text { implied mean }\end{array}$} & \multirow{2}{*}{$\begin{array}{l}\text { Expected inflation, } \\
\text { point prediction } \\
\text { (control group) }\end{array}$} & \multirow{2}{*}{$\begin{array}{l}\text { Perceived } \\
\text { inflation, } \\
\text { point } \\
\text { prediction } \\
\end{array}$} & \multirow{2}{*}{$\begin{array}{l}\text { Observations with } \\
\text { point predictions } \\
\text { and perceptions } \\
\text { for inflation }\end{array}$} & \multirow{2}{*}{$\begin{array}{c}\text { Expected UR, } \\
\text { point } \\
\text { prediction }\end{array}$} & \multirow{2}{*}{$\begin{array}{l}\text { Perceived UR, } \\
\text { point } \\
\text { prediction }\end{array}$} & \multirow{2}{*}{$\begin{array}{l}\text { Observations with } \\
\text { point predictions } \\
\text { and perceptions } \\
\text { for UR }\end{array}$} \\
\hline$\#$ & Date & & & & & & & \\
\hline & & $(1)$ & $(2)$ & (3) & (4) & (5) & (6) & (7) \\
\hline 1 & 2018Q2 & 22,582 & 2,511 & 22,582 & 2,511 & 22,582 & 22,582 & 22,582 \\
\hline 2 & 2018Q3 & 40,246 & - & 40,246 & - & - & 40,246 & - \\
\hline 3 & 2018Q4 & 31,781 & 4,556 & 31,781 & 4,556 & - & 31,781 & - \\
\hline 4 & 2019Q1 & 26,920 & 1,604 & 26,920 & 1,604 & 26,920 & 26,920 & 26,920 \\
\hline 5 & 2019Q2 & 28,566 & - & 28,566 & - & 28,566 & 28,566 & 28,566 \\
\hline 6 & 2019Q3 & 15,905 & - & 15,905 & - & 15,905 & 15,905 & 15,905 \\
\hline 7 & 2020Q1 & 21,197 & 5,519 & 21,197 & 5,519 & 21,197 & 21,197 & 21,197 \\
\hline 8 & 2020Q2 & 13,733 & 1,369 & 13,733 & 1,369 & 13,733 & 13,733 & 13,733 \\
\hline 9 & 2020Q3 & 12,878 & 6,409 & 6,401 & - & 6,429 & 12,844 & 6,429 \\
\hline 10 & 2020Q4 & 19,597 & 9,814 & - & - & 19,597 & 19,597 & 19,597 \\
\hline 11 & 2021Q1 & 26,262 & 13,156 & 13,120 & - & 13,115 & 26,262 & 13,115 \\
\hline 12 & 2021Q2 & 18,822 & 7,918 & 7,914 & - & 9,425 & 18,822 & 9,425 \\
\hline
\end{tabular}

Notes: The table shows the distribution of available survey responses by wave and question type. 
Table 2. Perceived and Expected Inflation across U.S. Households.

\begin{tabular}{lccccccccc}
\hline \hline & \multicolumn{10}{c}{ Sample } \\
\cline { 2 - 10 } $\begin{array}{c}\text { Dependent variable: } \\
\text { expected inflation, } \\
\text { point prediction }\end{array}$ & All & Female & Male & $\begin{array}{c}\text { Less } \\
\text { than } 45 \\
\text { years old }\end{array}$ & $\begin{array}{c}46-64 \\
\text { years old }\end{array}$ & $\begin{array}{c}\text { 65 or } \\
\text { more } \\
\text { years old }\end{array}$ & $\begin{array}{c}\text { Below } \\
\text { median } \\
\text { household } \\
\text { income }\end{array}$ & $\begin{array}{c}\text { Above } \\
\text { median } \\
\text { household } \\
\text { income }\end{array}$ \\
\cline { 2 - 11 } & $(1)$ & $(2)$ & $(3)$ & $(4)$ & $(5)$ & $(6)$ & $(7)$ & $(8)$ \\
\hline Perceived inflation & $0.44^{* * *}$ & $0.44^{* * *}$ & $0.45^{* * *}$ & $0.45^{* * *}$ & $0.43^{* * *}$ & $0.45^{* * *}$ & $0.44^{* * *}$ & $0.44^{* * *}$ \\
& $(0.01)$ & $(0.01)$ & $(0.02)$ & $(0.01)$ & $(0.01)$ & $(0.02)$ & $(0.01)$ & $(0.01)$ \\
\hline Observations & 11,196 & 8,380 & 2,816 & 3,382 & 4,718 & 3,096 & 5,950 & 5,246 \\
R-squared & 0.48 & 0.48 & 0.49 & 0.54 & 0.46 & 0.44 & 0.51 & 0.44 \\
\hline \hline
\end{tabular}

Notes: The table presents Huber regressions of the expected level inflation of households for the next twelve months on their perceived levels of inflation over the last twelve months. Column (1) is for all available respondents while columns (2)-(8) are for subsets of households. The cross-sectional unit of analysis is a respondent in the survey. The time series unit is the survey wave (quarter). Robust standard errors are reported in parentheses. ${ }^{* * *},{ }^{* *}, *$ denote statistical significance at 1,5 and 10 percent levels. 
Table 3. Predictive Power of Realized and Perceived Inflation.

\begin{tabular}{lccc}
\hline \hline Dep. var.: expected inflation (implied mean) & $(1)$ & $(2)$ & $(3)$ \\
\hline \hline Perceived inflation & $0.137^{* * *}$ & & $0.137^{* * *}$ \\
& $(0.006)$ & & $(0.006)$ \\
Realized inflation & $0.006^{* *}$ & $0.007^{* *}$ & \\
& $(0.003)$ & $(0.003)$ & \\
\hline Observations & 45,477 & 45,477 & 45,477 \\
R-squared & 0.040 & 0.000 & 0.040 \\
\hline \hline
\end{tabular}

Notes: the table shows results for Huber robust regressions where the dependent variable is expected inflation rate (implied mean; reported in the survey) and the regressors are the realized inflation rate (reported in the Nielsen Homescan Panel) and the perceived inflation rate (reported in the survey). The cross-sectional unit of analysis is a household. The time series unit is the survey wave (quarter). Robust standard errors are reported in parentheses. ***, **, * denote statistical significance at 1, 5 and 10 percent levels. 
Table 4. Revisions in expected inflation and unemployment rates.

\begin{tabular}{lcccc}
\hline & \multicolumn{3}{c}{ Dependent variable: revision in expected unemployment rate } \\
\cline { 2 - 5 } & OLS & OLS & IV & IV \\
\cline { 2 - 5 } & $(1)$ & $(2)$ & $(3)$ & $(4)$ \\
\hline \hline Revision in expected inflation rate & $0.174^{* * *}$ & $0.172^{* * *}$ & $0.462^{* * *}$ & $0.448^{* * *}$ \\
& $(0.011)$ & $(0.011)$ & $(0.053)$ & $(0.052)$ \\
\hline Controls & No & Yes & No & Yes \\
Observations & 8,900 & 8,900 & 8,900 & 8,900 \\
R-squared & 0.038 & 0.043 & -0.066 & -0.052 \\
$1^{\text {st }}$ stage F-stat & & & 116.3 & 113.5 \\
\hline \hline
\end{tabular}

Notes: The table report estimates for the specification where we regress revisions in expected unemployment rate on revisions in expected inflation rate. In columns (3) and (4) revisions in expected inflation rate are instrumented with revisions in perceived inflation rate. The revisions are computed as average expectations in the COVID19 period minus average expectations in the pre-COVID period. Household controls in columns (2) and (4) are included but not reported. Robust standard errors are in parentheses. ***, **, * denote statistical significance at 1,5 and 10 percent levels. 


\section{APPENDIX FIGURES AND TABLES}




\section{$\underline{\text { Panel A: Distribution of Expected Inflation from Point Forecasts }}$}

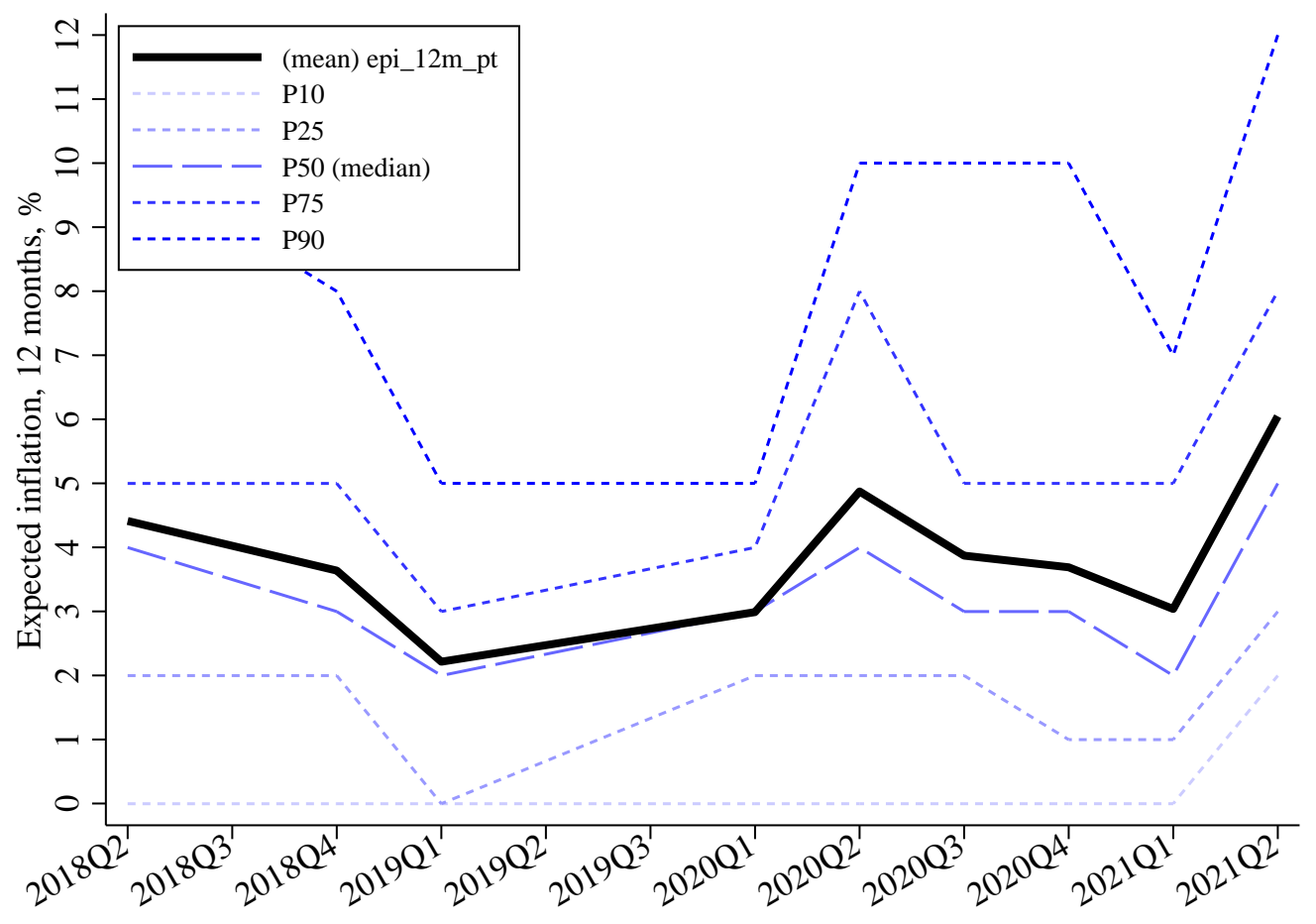

Panel B: Distribution of Expected Inflation from Implied Means

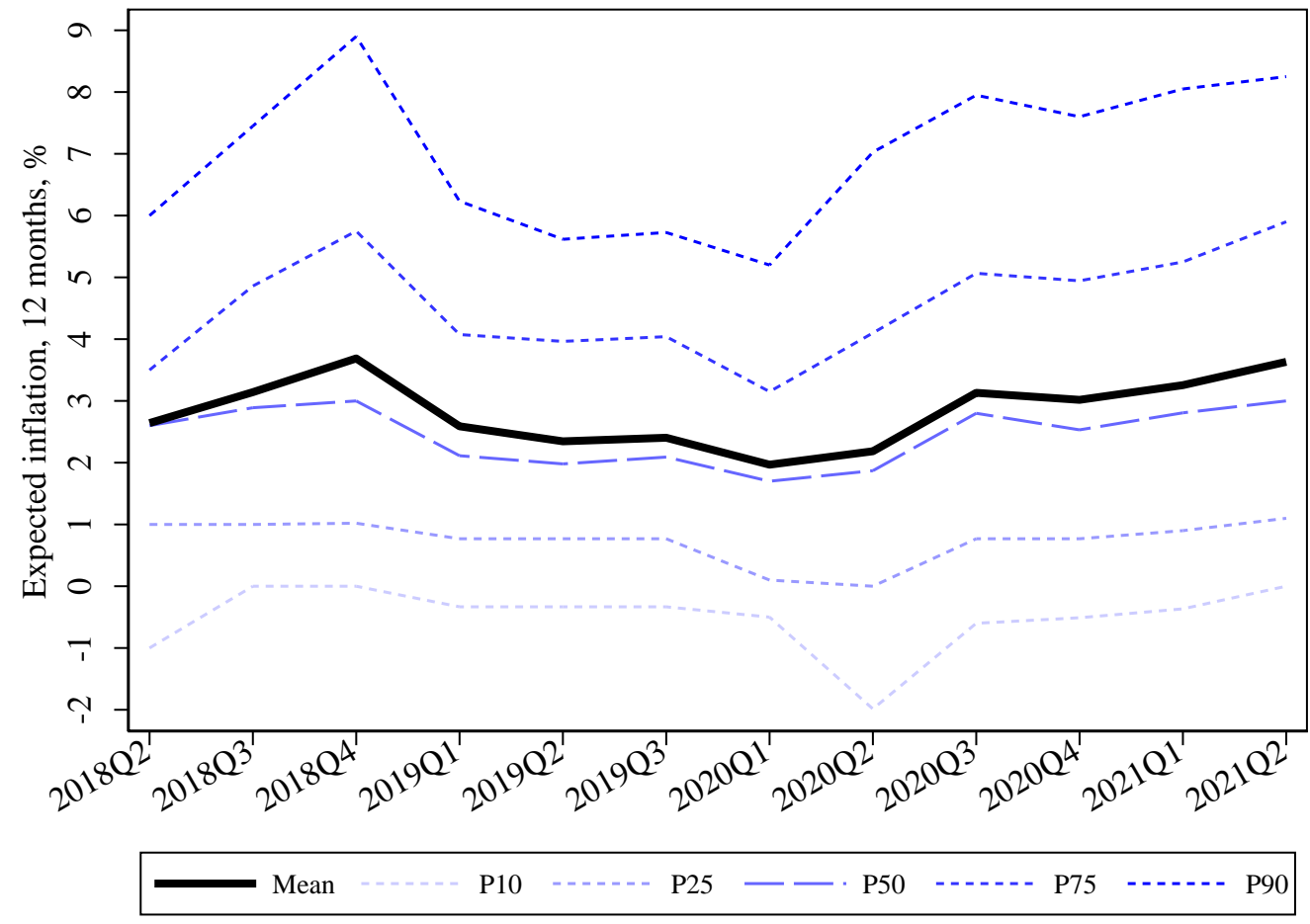

Notes: The figure plots Huber estimates of the different percentiles of the cross-sectional distribution of survey respondents' expected inflation over the next 12 months (Panel A) and perceived inflation over the last 12 months (Panel B). 
Appendix Figure 2. Distribution of Perceived Inflation of U.S. Households

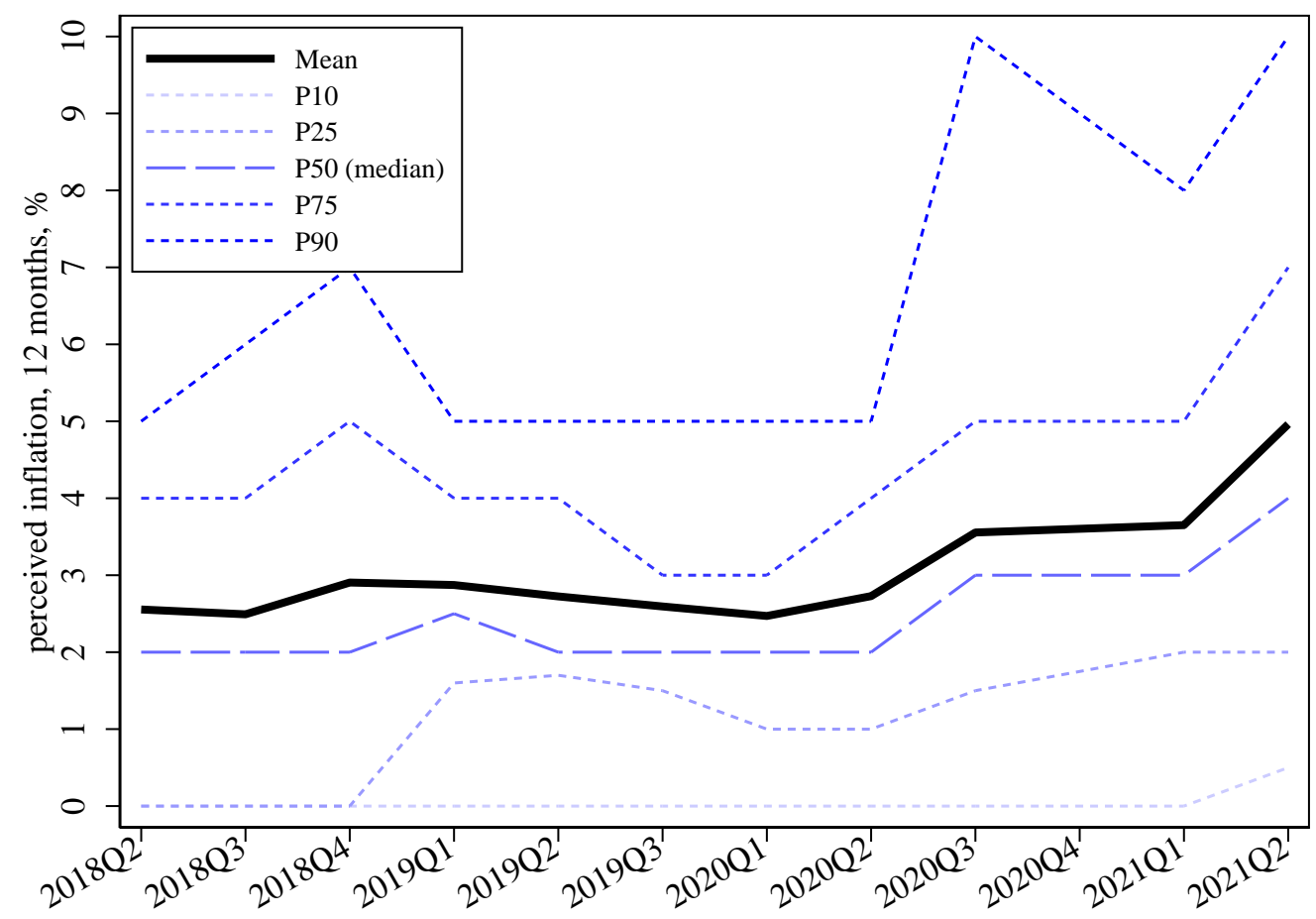

Notes: The figure plots Huber estimates of the different percentiles of the cross-sectional distribution of survey respondents' perceived inflation over the last 12 months. 
Appendix Figure 3. Distribution of expected and perceived unemployment rate.

Panel A. Expected unemployment rate.

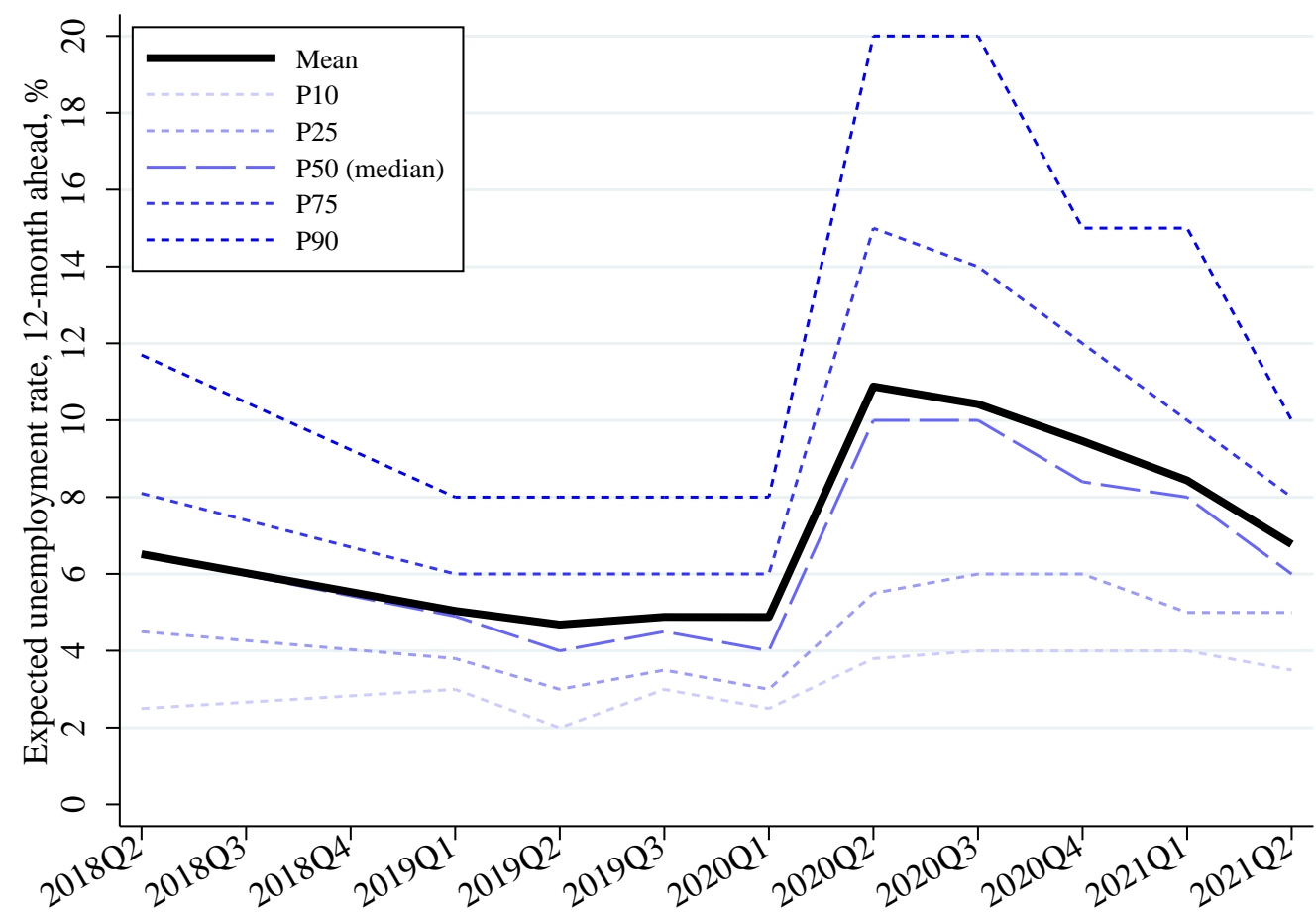

Panel B. Perceived unemployment rate.

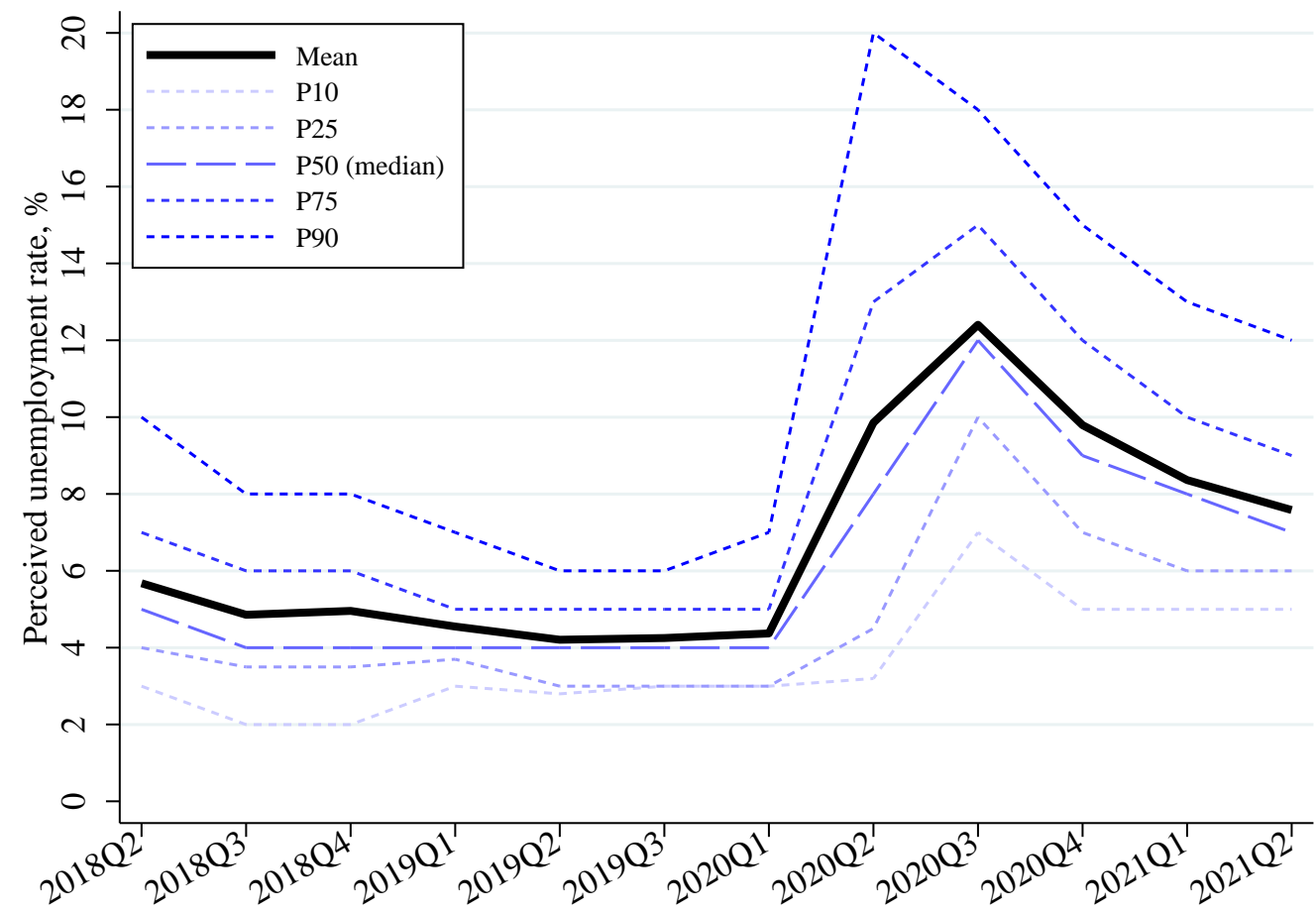

Notes: The figure plots Huber estimates of the different percentiles of the cross-sectional distribution of survey respondents' perceived and expected unemployment rate. 
Appendix Figure 4. Distribution of Realized Inflation of U.S. Households, by Region.

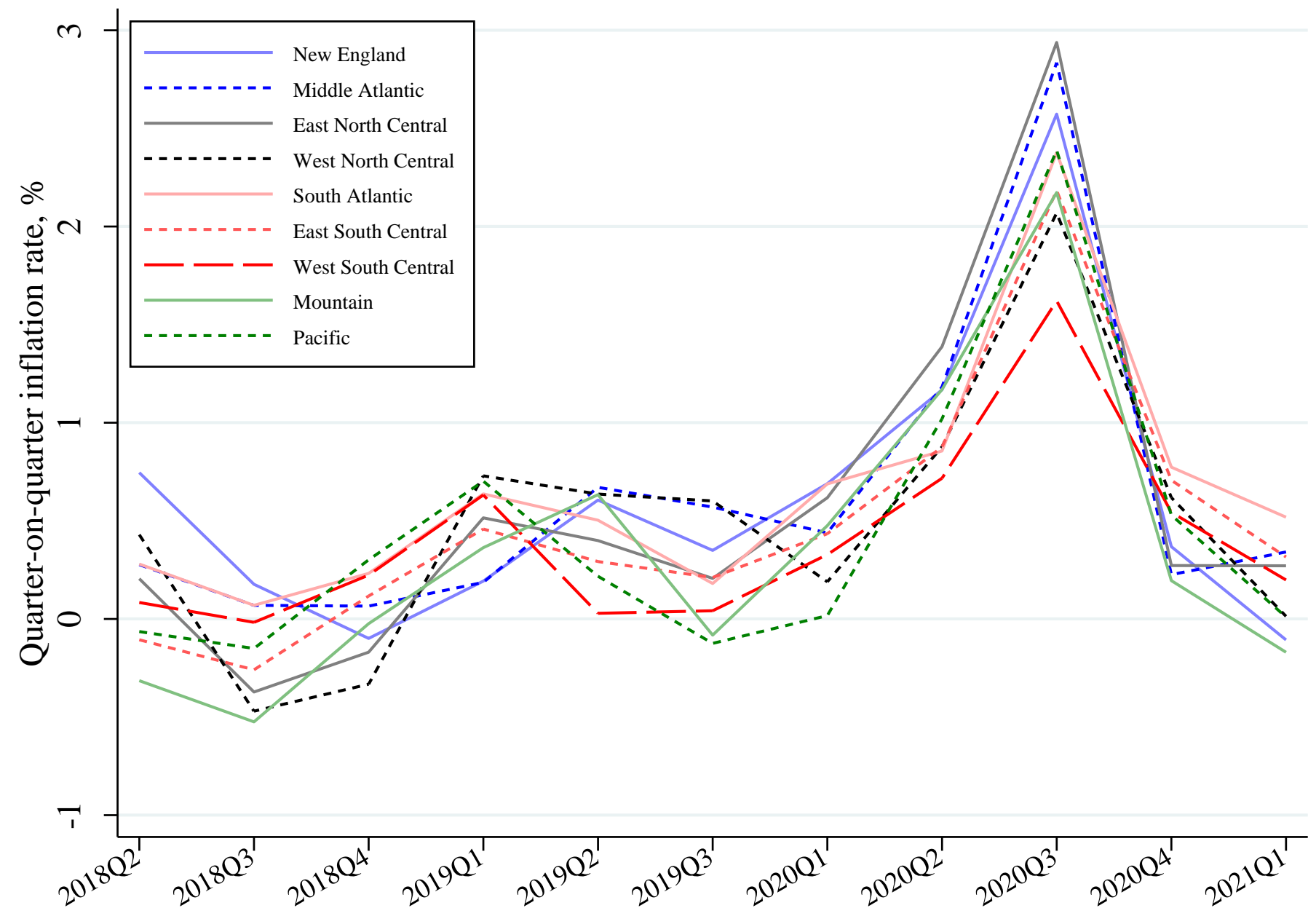

Notes: the figure plots time series of inflation rate realized for various groups of households in the Nielsen Homescan Panel. 


\section{Panel A: Realized and Expected Inflation by Education}
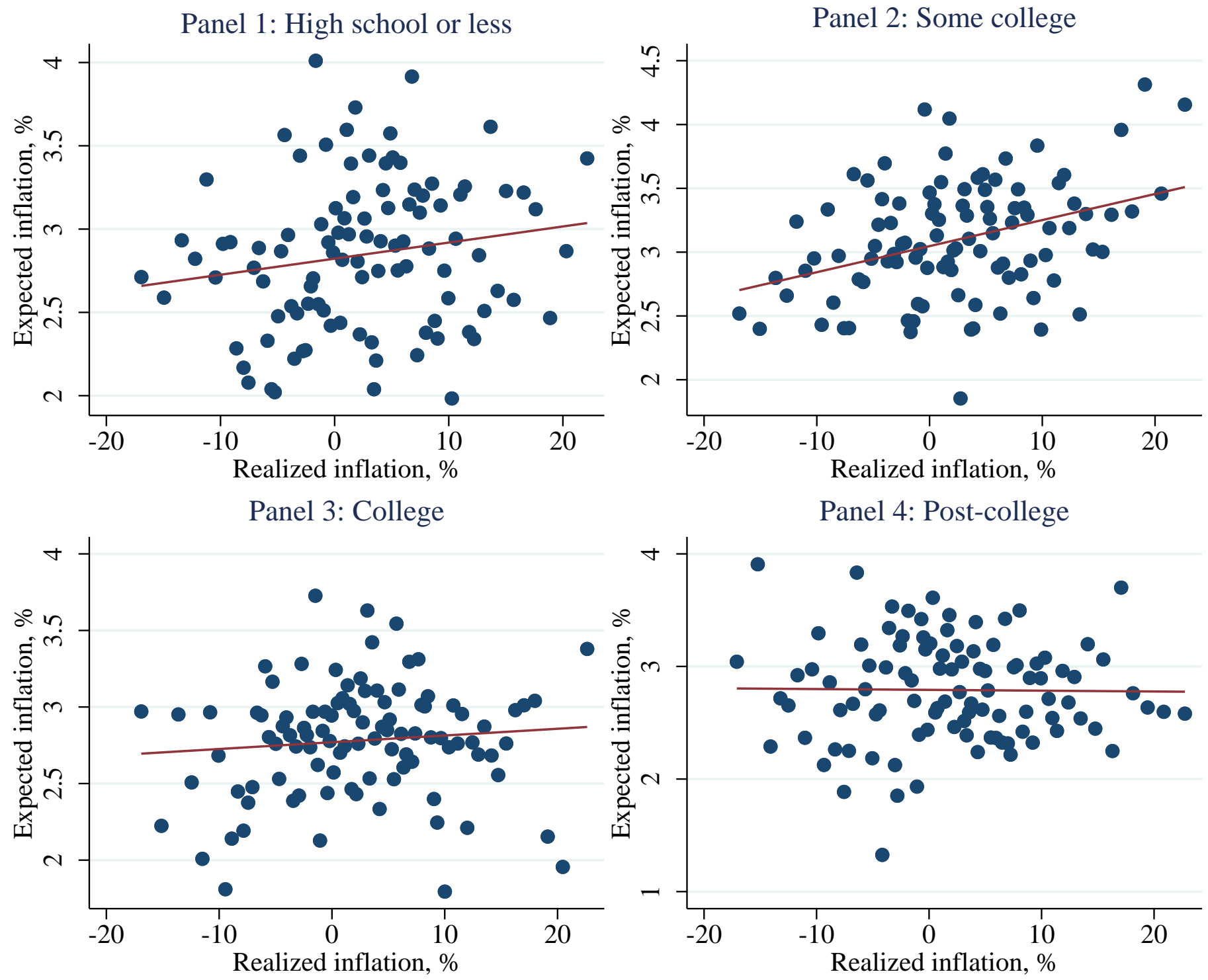

Notes: The figure shows binscatters of realized inflation (x-axis) in the Nielsen Homescan Panel and expected inflation (y-axis; implied mean) in the survey for various demographic groups. 
Panel B: Realized and Expected Inflation by Income
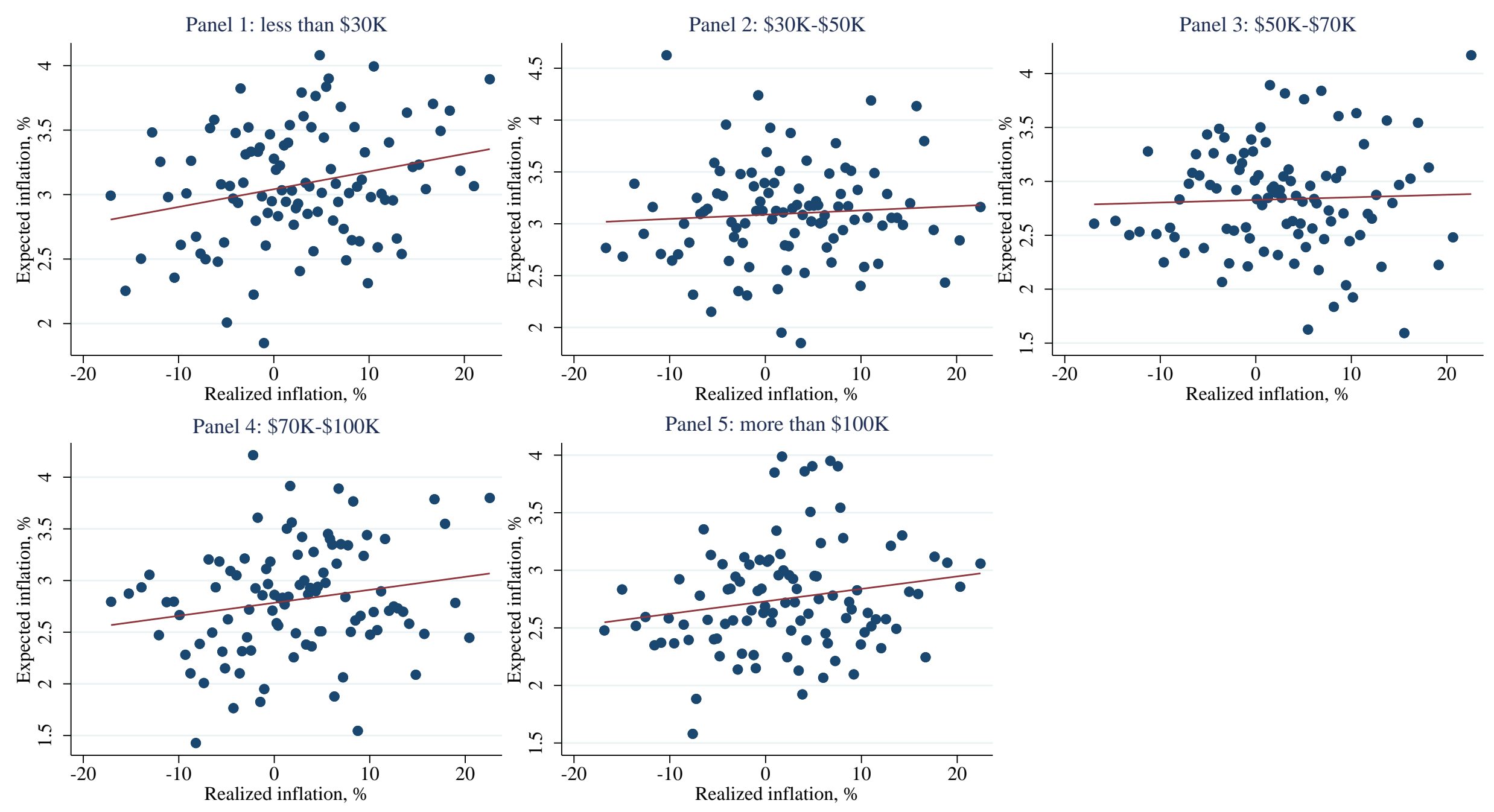

Notes: The figure shows binscatters of realized inflation (x-axis) in the Nielsen Homescan Panel and expected inflation (y-axis; implied mean) in the survey for various demographic groups. 
Panel C: Realized and Expected Inflation by Age
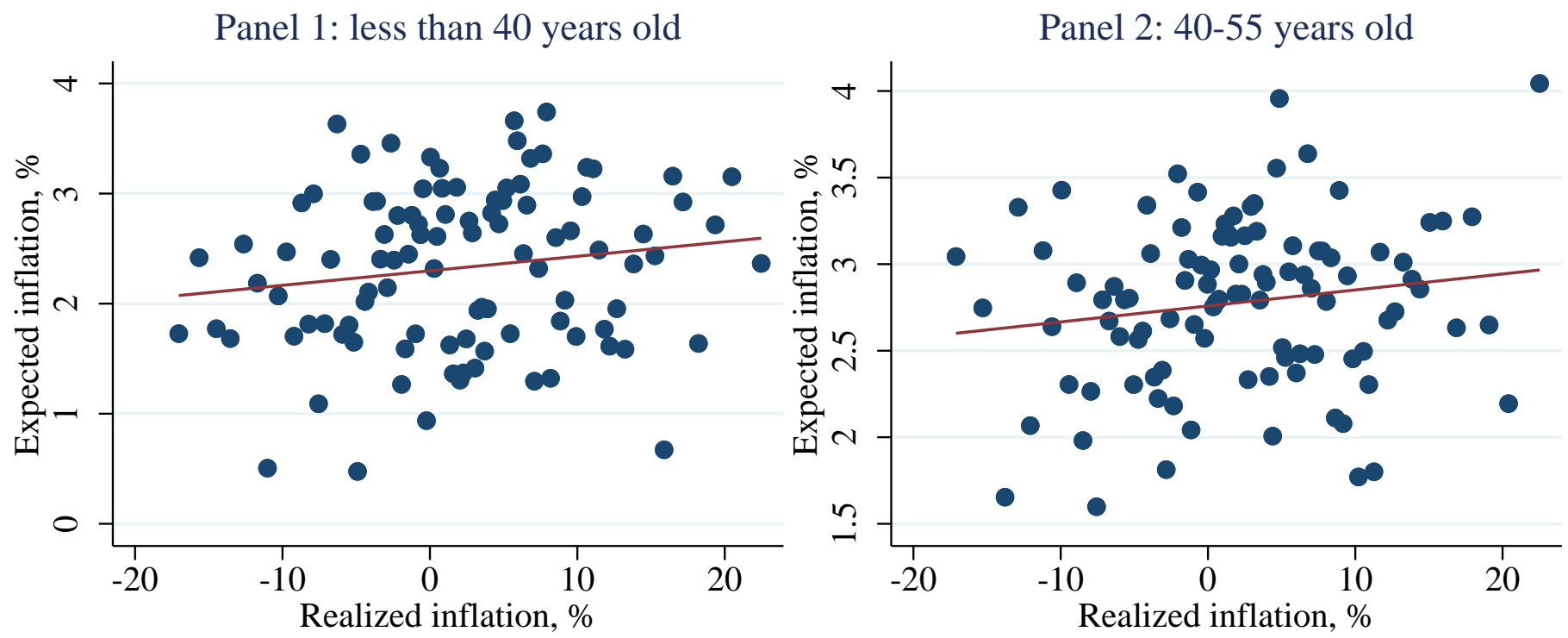

Panel 3: 55-65 years old

Panel 4: more than 65 years old
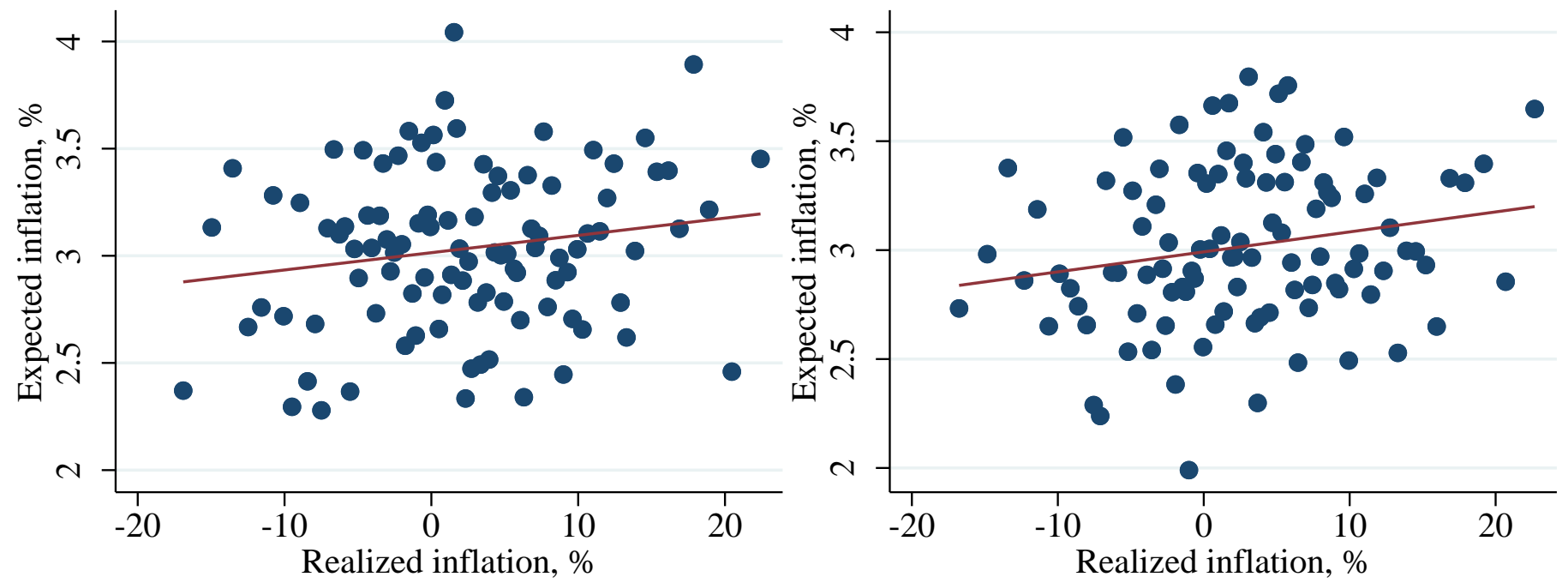

Notes: The figure shows binscatters of realized inflation (x-axis) in the Nielsen Homescan Panel and expected inflation (y-axis; implied mean) in the survey for various demographic groups. 

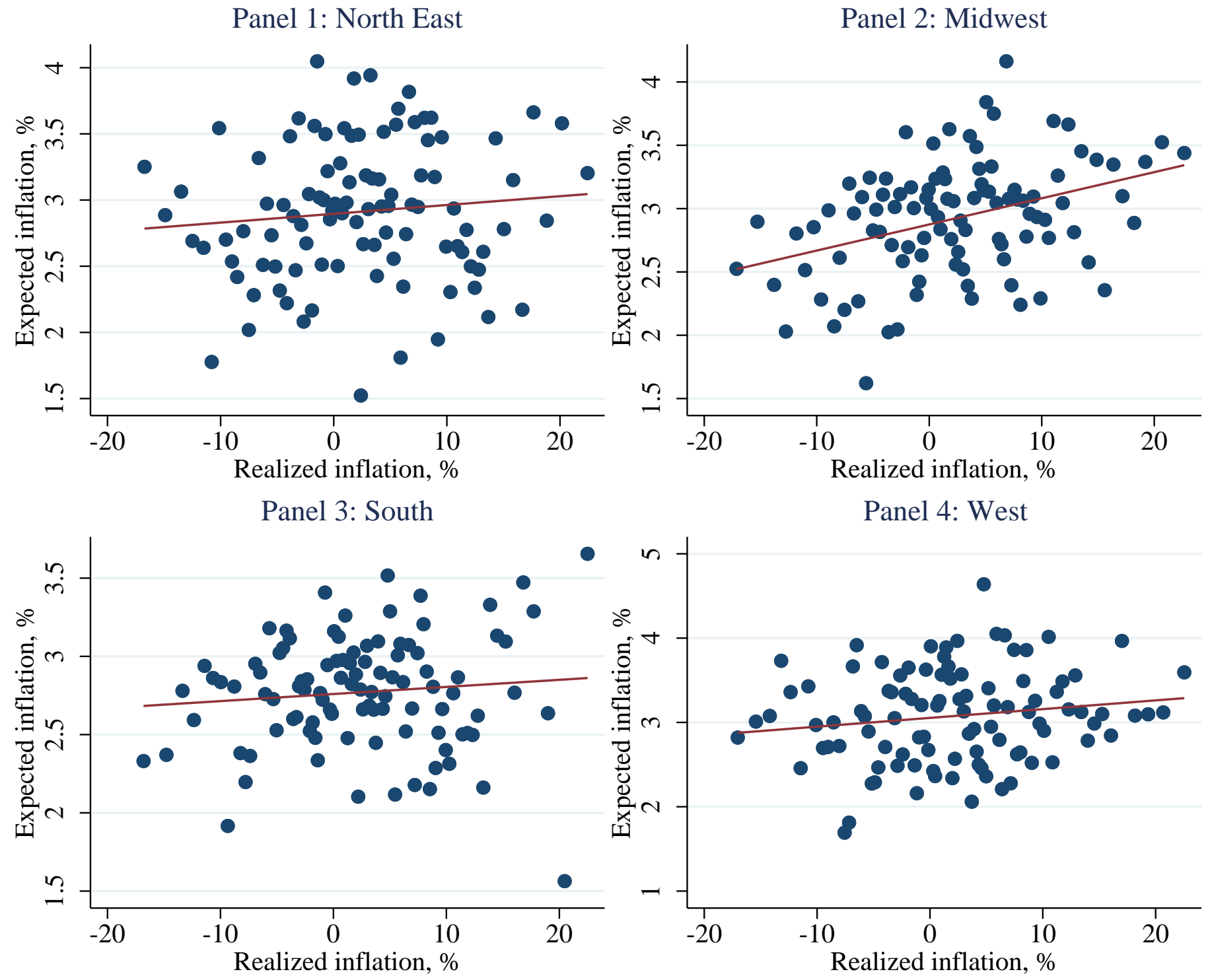

Notes: The figure shows binscatters of realized inflation (x-axis) in the Nielsen Homescan Panel and expected inflation (y-axis; implied mean) in the survey for various demographic groups. 


\section{Panel A: Inflation and Unemployment Expectations by Race}
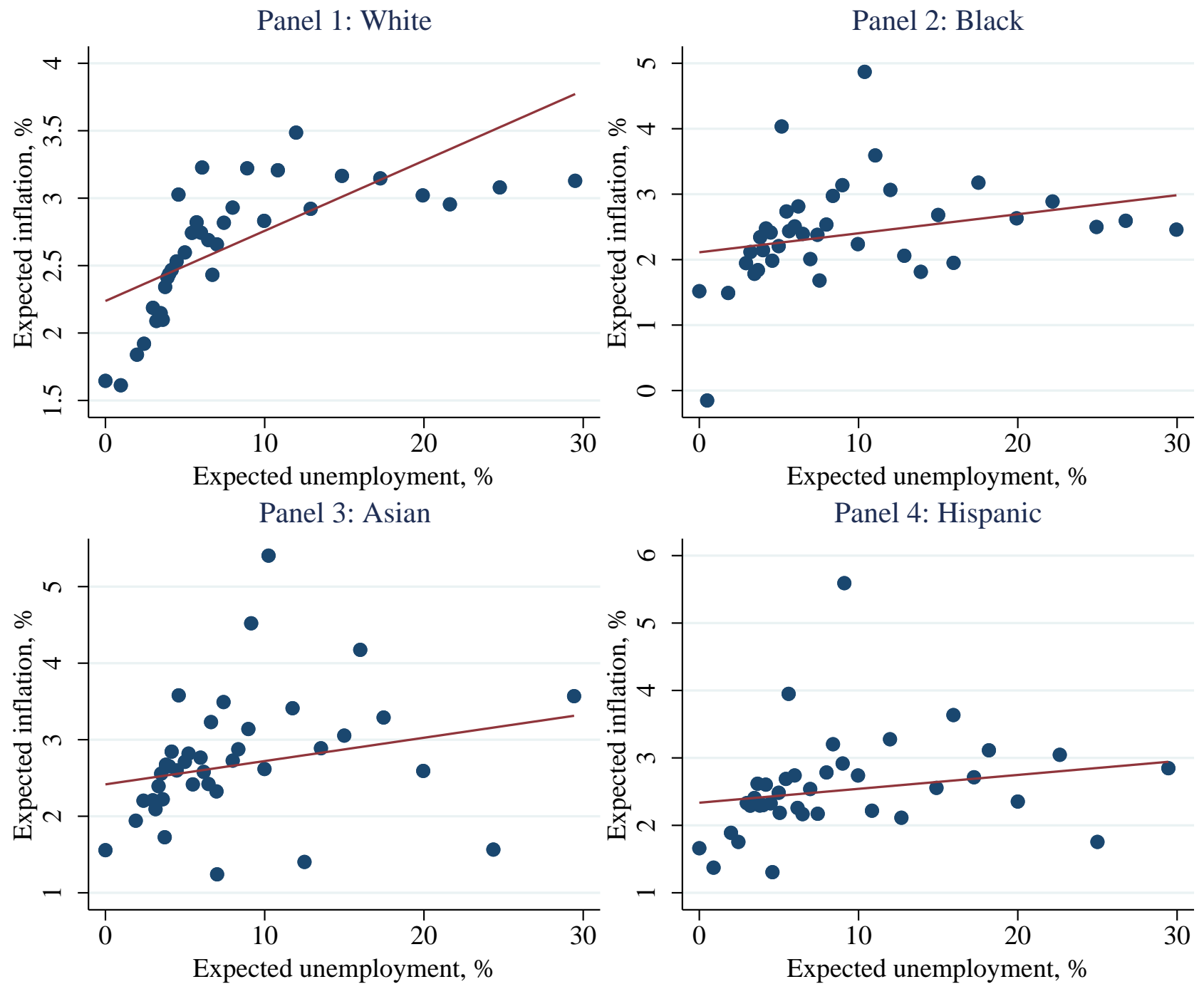

Notes: The figure shows binscatters of expected unemployment (x-axis) and expected inflation (y-axis) in the survey for various demographic groups. 
Appendix Figure 6. Inflation and Unemployment Expectations (continued)

Panel B: Inflation and Unemployment Expectations by Education
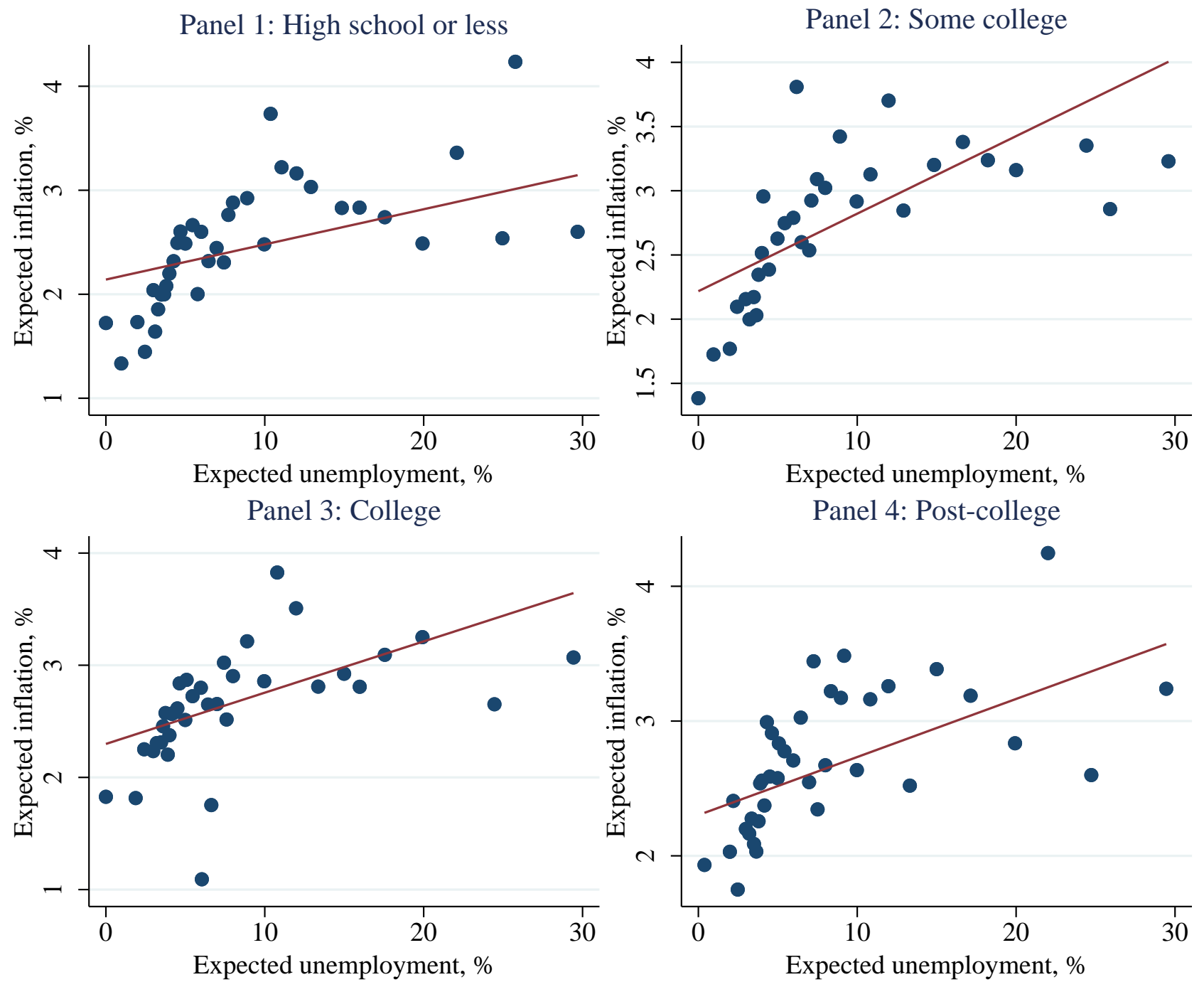

Notes: The figure shows binscatters of expected unemployment (x-axis) and expected inflation (y-axis) in the survey for various demographic groups. 


\section{Appendix Figure 6. Inflation and Unemployment Expectations (continued)}

\section{Panel C: Inflation and Unemployment Expectations by Income}
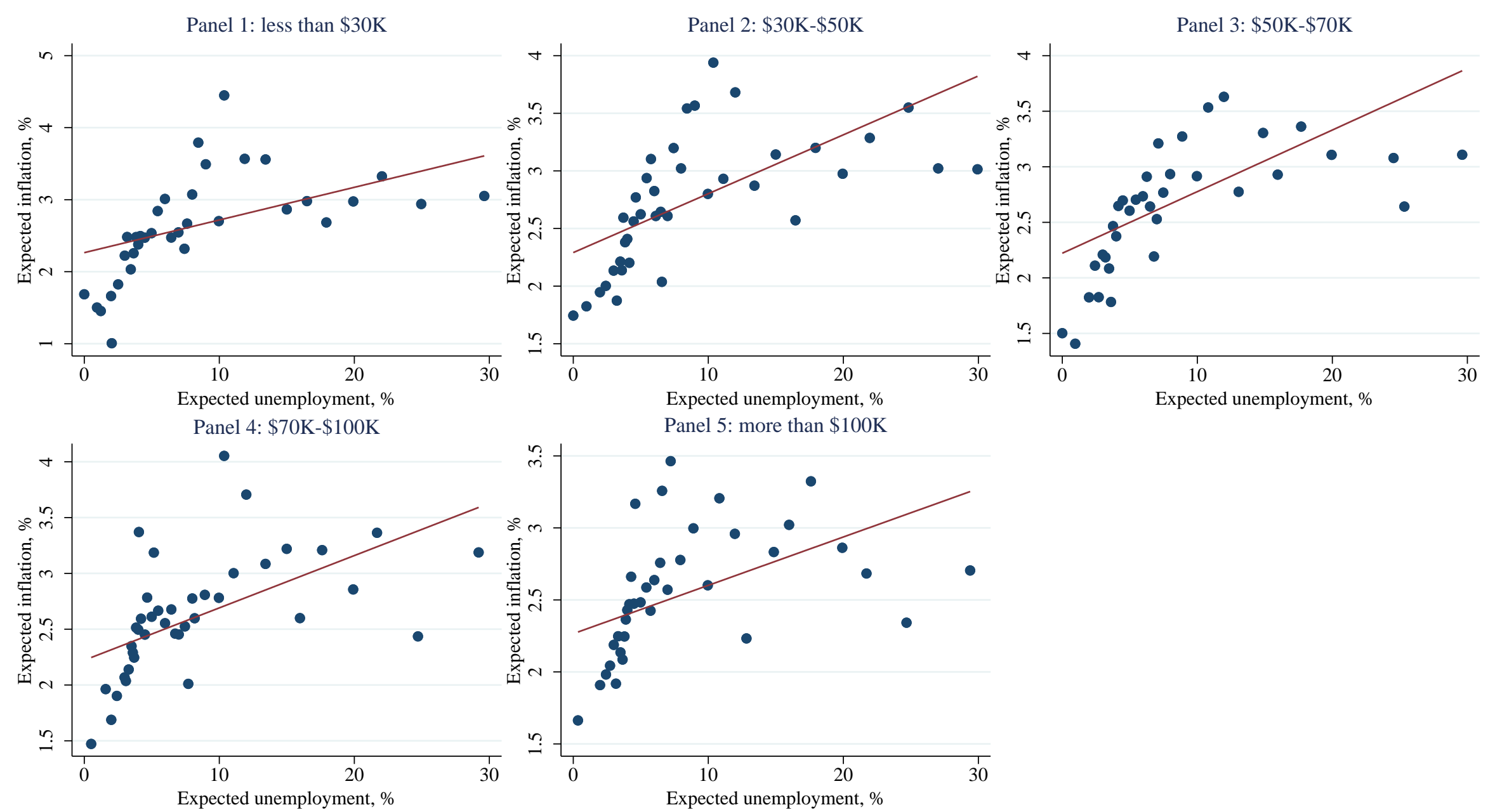

Notes: The figure shows binscatters of expected unemployment (x-axis) and expected inflation (y-axis) in the survey for various demographic groups. 


\section{Panel D: Inflation and Unemployment Expectations by Age}
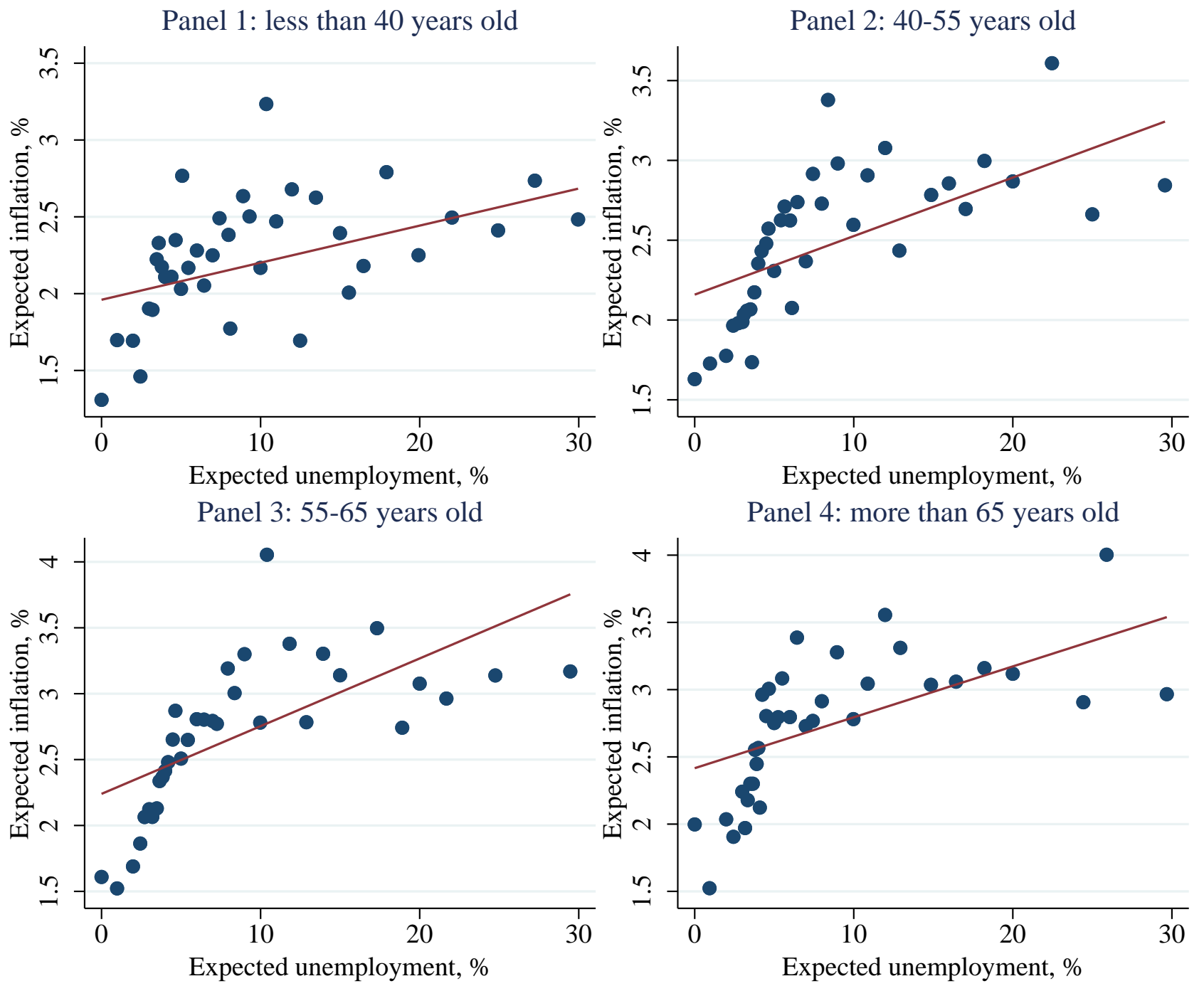

Notes: The figure shows binscatters of expected unemployment (x-axis) and expected inflation ( $y$-axis) in the survey for various demographic groups. 
$\underline{\text { Panel E: Inflation and Unemployment Expectations by Region }}$
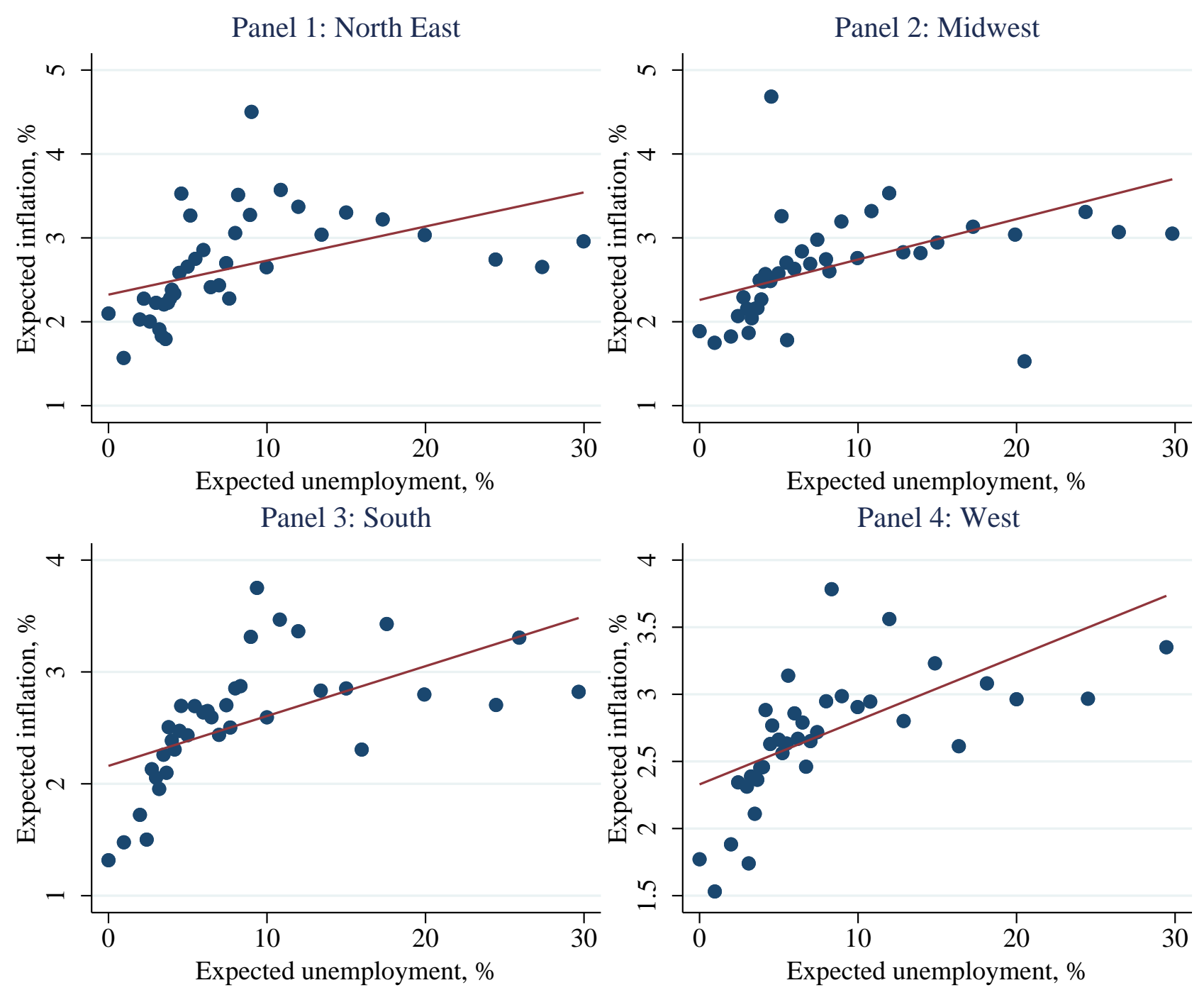

Notes: The figure shows binscatters of expected unemployment (x-axis) and expected inflation ( $\mathrm{y}$-axis) in the survey for various demographic groups. 
Appendix Table 1. The Realized Inflation of Households and Their Expected Levels of Inflation.

Dependent variable: Expected

Inflation

\begin{tabular}{lccccc} 
Realized inflation & $0.010^{* * *}$ & $0.010^{* * *}$ & $0.010^{* * *}$ & $0.006^{* *}$ & $0.006^{* *}$ \\
& $(0.003)$ & $(0.003)$ & $(0.003)$ & $(0.003)$ & $(0.003)$ \\
\hline Household characteristics & No & Yes & No & No & Yes \\
Household fixed effects & No & No & Yes & No & No \\
Time fixed effects & No & No & No & Yes & Yes \\
Observations & 57,727 & 57,727 & 50,296 & 57,727 & 57,727 \\
R-squared & 0.000 & 0.004 & 0.488 & 0.008 & 0.012 \\
\hline
\end{tabular}

Notes: the table shows results for regressions where the dependent variable is expected inflation (implied mean) and the regressors are the realized inflation rate (reported in the Nielsen Homescan Panel) and controls. The cross-sectional unit of analysis is a household. The time series unit is the survey wave (quarter). Robust standard errors are reported in parentheses. ${ }^{* * *},{ }^{* *},{ }^{*}$ denote statistical significance at 1,5 and 10 percent levels. 